Review Article

\title{
Mitochondrial Cytochrome c Oxidase: Catalysis, Coupling and Controversies
}

\author{
Peter R. Rich \\ Glynn Laboratory of Bioenergetics, Institute of Structural and Molecular \\ Biology, University College London, Gower Street, London WC1E 6BT, \\ U.K.
}

Correspondence: Peter Rich (prr@ucl.ac.uk) 


\begin{abstract}
Mitochondrial cytochrome $c$ oxidase is a member of a diverse superfamily of haem-copper oxidases. Its mechanism of oxygen reduction is reviewed in terms of the cycle of catalytic intermediates and their likely chemical structures. This reaction cycle is coupled to the translocation of protons across the inner mitochondrial membrane in which it is located. The likely mechanism by which this occurs, derived in significant part from studies of bacterial homologues, is presented. These mechanisms of catalysis and coupling, together with current alternative proposals of underlying mechanisms, are critically reviewed.
\end{abstract}

\title{
Abbreviations
}

$\mathrm{CcO}$, cytochrome $c$ oxidase; BNC, binuclear center; IMS, mitochondrial intermembrane space; IMM, inner mitochondrial membrane; PMF, protonmotive force; $E_{m(x)}$, midpoint potential at $(\mathrm{pH} x) ; E_{h(x)}$, operative potential at $(\mathrm{pH} x) ; \mathrm{H}_{\mathrm{N}}{ }^{+}$, protons in the Negative aqueous phase (the matrix space in mitochondria); $\mathrm{H}_{\mathrm{P}}{ }^{+}$, protons in the Positive aqueous phase (the IMM and cytoplasm in eukaryotes); PCET, proton-coupled electron transfer; FTIR, Fourier transform infrared. 


\section{Introduction}

Electron flow along mitochondrial respiratory chains is dependent on a constant supply of oxygen, which provides the final sink for the electrons by being reduced to water. In mammalian mitochondria, this oxygenreducing function is catalysed by cytochrome $c$ oxidase $(\mathrm{CcO})$, a multisubunit complex that spans the inner mitochondrial membrane (Figure 1). Electrons provided by reduced cytochrome $c$ in the intermembrane space (IMS) are firstly donated to a dinuclear copper centre $\left(\mathrm{Cu}_{\mathrm{A}}\right)$. From here, they are transferred through a low spin haem A (haem a) into the catalytic site, termed the binuclear centre (BNC), that is formed by a second haem $A\left(\right.$ haem $a_{3}$ ) and a copper atom $\left(\mathrm{Cu}_{B}\right)$ (Figure 1). The BNC binds molecular oxygen, reducing it to two waters with four electrons from cytochrome $c$ in the IMS and four protons from the mitochondrial matrix. The BNC is buried in the membrane spanning region of the protein, lying approximately $1 / 3$ of the distance across the membrane from the positive aqueous phase of the IMS. Because the positive protons come from the matrix and negative electrons from the IMS, their transfer to the $\mathrm{BNC}$ creates a $\mathrm{pH}$ and electrical charge difference across the membrane in which the $\mathrm{CcO}$ is embedded ( $\mathrm{N}$ phase matrix and $\mathrm{P}$ phase IMS). As a result, part of the energy released by the exergonic oxygen reduction reaction is conserved in the transmembrane electrochemical proton gradient (or protonmotive force, PMF), as envisaged in the chemiosmotic proposals of Mitchell (1). With a typical PMF of $\sim 200 \mathrm{mV}$ (mostly $\Delta \varphi$ ), only $35-40 \%$ of the available energy of oxygen reduction $\left(E_{\mathrm{h}}=+815 \mathrm{mV}\right.$ at $\mathrm{pH} 7$ ) by cytochrome $c$ (if $50 \%$ reduced i.e. $E_{h}=E_{m}=+260 m V$ ) would be conserved from the four vectorial electron and proton transfers required to reduced dioxygen. However, each full catalytic cycle also causes an additional four protons to be translocated from the matrix to the IMS (2), hence increasing the fraction of energy that can be stored in the PMF to $\sim 75 \%$ when operating against a large PMF.

Overall, combining the oxygen reduction reaction with the coupled proton translocations, a complete reaction cycle is given by the equation:

4 cyt $c^{2+}+\mathrm{O}_{2}+8 \mathrm{H}_{\mathrm{N}}^{+} \rightarrow 4$ cyt $^{3+}+2 \mathrm{H}_{2} \mathrm{O}+4 \mathrm{H}_{\mathrm{P}}^{+}$

Tremendous progress has been made in resolving atomic structures of several $\mathrm{CcO}$ s by X-ray crystallography and in elucidating the complex chemistry of oxygen reduction by a range of kinetic and spectroscopic methods. More challenging has been the detailed resolution of the intricately-linked pathways for passage of protons through the protein 
structure and the mechanism by which these are driven by the exothermic oxygen reduction chemistry. This has required a wide range of additional biophysical methods, and has been greatly aided by studies of specific mutations and their effects. Progress and outstanding questions on these topics are the subject of this review.

\section{Structure}

\section{The Haem-Copper Oxidase (HCO) Superfamily}

Mitochondrial $\mathrm{CcOs}$ are members of a haem-copper oxidase (HCO) superfamily, examples of which are found throughout eukarya, bacteria and archaea (3-5). The common feature of all is the presence of a homologous core subunit (subunit I) that houses a bis-histidine coordinated low spin haem and a catalytic BNC formed from a histidineligated high spin haem and a copper ion ligated by three histidine ligands, one of which is covalently linked via its $\mathrm{N}_{\mathrm{T}}$ nitrogen to the meta ring carbon of a catalytic tyrosine (6) (Figure 2). The haem $\mathrm{a}_{3}$ and $\mathrm{Cu}_{\mathrm{B}}$ metals are separated by around $5 \AA$ and form the site in which oxygen can bind during the catalytic cycle. It seems likely that all HCOs are coupled to some extent to the transmembrane movement of protons that are in addition to those required for oxygen reduction.

Mitochondrial $\mathrm{CcOs}$ belong to the $\mathrm{A} 1$ subgroup of $\mathrm{HCOs,} \mathrm{which} \mathrm{also}$ includes closely-related bacterial $\mathrm{CcOs}$ and quinol oxidases. Atomic structural details are available of bovine mitochondrial (6) several A1type bacterial $\mathrm{CcOs}(7,8)$ and the A1-type quinol oxidase cytochrome bo (9). The structure of an A2 type, $\mathrm{caa}_{3}$ from $T$. thermophilus, has also been solved (10) which, although having the same basic features of the A1-types, is quite different in distribution of domains between subunits and with a tyrosine most replacing the proton-transferring function of a key glutamic acid that is conserved in the A1 HCOs $(11,12)$. The superfamily includes two other subgroups of HCOs, the B- and C-types (with available atomic structures of B-type $b a_{3}(13,14)$ and C-type $c b b_{3}$ (15)). It also includes a range of membrane-bound nitric oxide reductases (NORs) $(5,16)$; these again have a homologous subunit I, though a non-haem iron replaces $\mathrm{Cu}_{\mathrm{B}}$, lack the catalytic tyrosine and, at least for those tested, are not linked to proton translocation (17). These additional types have been reviewed elsewhere and will not be discussed in detail here.

The A-type HCOs have the same common core of three protein subunits: I, II and, unique to the A subgroup, subunit III. In the $\mathrm{CcOs}$, 
subunit II houses the dinuclear $\mathrm{Cu}_{\mathrm{A}}$ cofactor (Figure 1) that acts as the immediate acceptor of electrons from soluble cytochrome $c$. In the quinol oxidases this metal site is absent and instead the likely binding site for the quinol donor is provided by a polar region of subunit I within the lipid bilayer (9). Subunit III has no cofactors but may provide a selective lipidlined channel through which substrate oxygen diffuses from the membrane interior to an entry point on subunit I to the BNC (18). It may also have a proton collection function at the entrance to the $D$ channel $(19,20)$

Subunit I is the largest of the core subunits, and is composed of twelve (in mammalian) or more membrane-spanning $\alpha$-helices that, when viewed perpendicular to the membrane surface, are organized in three groups of four helices in the form of a cloverleaf (7). It houses the low spin haem and the BNC (Figure 2) together with clusters of hydrophilic amino acids and water molecules (Figure 3 ) that could provide protonconducting channels. Two of these, the $\mathrm{K}$ and $\mathrm{D}$ channels, are very similar in all A-type HCOs. The $\mathrm{K}$ channel leads from the $\mathrm{N}$ phase, possibly with an opening between subunits I and II (21), towards the BNC. The D channel connects an aspartate (D91) at the $\mathrm{N}$ phase surface to a buried functional glutamic acid (A1-subtype) or tyrosine (A2subtype) located $\sim 10 \AA$ from both haem macrocycles and from $\mathrm{Cu}_{\mathrm{B}}$.

At least in bacterial $\mathrm{CcOs}$, the $\mathrm{K}$ channel provides the pathway for transfer of one or two of the 'substrate' protons required for oxygen reduction to water from the $\mathrm{N}$ phase into the $\mathrm{BNC}$. The $\mathrm{D}$ pathway is thought to provide part of the pathway from the $\mathrm{N}$ phase for the remaining substrate protons, together with part of the route for all four translocated protons (22). These roles are supported by a considerable body of data, in particular from studies of mutant forms of bacterial Atype $\mathrm{CcOs}$ (23). However, they also raise questions that are not yet fully resolved, as discussed below.

Whereas all HCOs appear to have a channel of some type in the region of the $\mathrm{K}$ channel, the presence of a catalytically-active $\mathrm{D}$ channel appears to be unique to the A-type HCOs (5). Since proton translocation has been demonstrated in B- and C-type HCOs that lack an active D channel (4), this suggests that coupling can be achieved with alternative proton pathways. This is further complicated by the presence of a third hydrophilic structure in A-type HCOs, the $\mathrm{H}$ channel. This complex structure was firstly described, and is particularly prominent, in mitochondrial $\mathrm{CcOs}(6)$. It could potentially provide a path for protons from the $\mathrm{N}$ phase to the region around the farnesyl $\mathrm{OH}$ and formyl group 
of low spin haem $a$ and from there, via a peptide bond gate and a more static $\mathrm{H}$-bonded network of amino acids and waters, to the aqueous $\mathrm{P}$ phase. As discussed below, this structure has been proposed to provide a proton translocation pathway (24) that may be unique to mammalian CcOs.

The mitochondrial $\mathrm{CcOs}$ are considerably larger than their bacterial counterparts because they have additional firmly-attached supernumerary subunits which, apart from a possible homologue of subunit IV in cyanobacteria (25), do not appear to have bacterial homologues. Human and bovine $\mathrm{CcOs}$ have 10 such subunits (26). Several more loosely-associated additional proteins have been identified that remain attached to free or supercomplex-bound mitochondrial $\mathrm{CcOs}$ when extracted with digitonin but are lost with harsher detergents. Specific functions of some supernumerary and additional subunits and their isoforms, their post-translational modifications and ligand binding sites have been suggested, though the supporting data in many cases remain inconsistent. Several are clearly involved in dimerisation and/or supercomplex formation (27-30). Reviews of possible functions have appeared recently and will not be discussed further here.

\section{Internal electron transfer}

The initial electron acceptor from cytochrome $c$ is the dinuclear $\mathrm{Cu}_{\mathrm{A}}$ centre that is housed in the hydrophilic domain of subunit II that extends into the $\mathrm{P}$ phase (the mitochondrial IMS or bacterial periplasm). The recent elucidation of the atomic structure of a horse heart cytochrome c/bovine CcO complex at high resolution (31) has confirmed the primarily electrostatic basis for complex formation $(32,33)$ and a plausible electron transfer route, The interface is provided almost entirely by subunit II and, unusually, has a large number of intercalated water molecules. It is unclear whether these waters are of functional significance as suggested (31), or whether they arise simply because of the suboptimal $\mathrm{pH}$ and/or the fact that both partners were in the oxidised state.

From here- $\mathrm{Cu}_{\mathrm{A}}$, the electronit is transferred to the low spin haem of subunit I and from there to the haem $a_{3}$ of the BNC. All four electrons required for a full catalytic cycle are sequentially passed from cytochromes $c$ into the BNC only via this $\mathrm{Cu}_{\mathrm{A}} \rightarrow$ haem $\mathrm{a} \rightarrow$ haem $\mathrm{a}_{3}$ pathway, despite similar short distances of $\mathrm{Cu}_{\mathrm{A}}$ to the macrocycle of haem $a(\sim 16 \AA)$ and haem $a_{3}(\sim 19 \AA)$ (Figure 1B). The explanation for this may arise from the fact that the redox potential of haem $a_{3}$ is strongly 
$\mathrm{pH}$-dependent. Hence, before protonation, its midpoint potential is much lower than that of haem $a$, though this explanation may not provide a complete answer for those intermediates ( $P$ and $F$ in Figure 4$)$ in which haem $a_{3}$ is thought to be in a highly oxidising ferryl state. It has also been suggested that the bound $\mathrm{Mg}^{++}$ion that lies roughly between $\mathrm{Cu}_{\mathrm{A}}$ and haem $a_{3}$ (Figure 1) may act as an insulator of some sort. As discussed below, this indirect electron transfer sequence to the BNC via the low spin haem is central to the coupled proton translocation mechanism. Though the haem metals are separated by $\sim 19 \AA$, the edges of the haem macrocycles come within $\sim 7 \AA$ (Figure 2). Therefore, electron transfer between them should be very fast (34) as has been confirmed experimentally (35).

\section{The catalytic cycle of oxygen reduction}

The basic catalytic cycle and the key intermediates are summarised in Figure 4. Electrons are delivered from cytochrome $c$ into the BNC individually by the pathway outlined above. Starting with the fully oxidized enzyme, $\mathrm{O}_{(\mathrm{H})}$, the first two electron transfers result in formation of the one-electron-reduced $\left(\mathrm{E}_{(\mathrm{H})}\right)$ state and then the two-electronreduced $(R)$ state of the BNC. It seems likely that purified forms of oxidised $\mathrm{CcO}(\mathrm{O}$ in Figure 4$)$ are in a state which differs from the oxidised form produced immediately after turnover $\left(\mathrm{O}_{\mathrm{H}}\right.$ in figure 4$)$. Reduction of $\mathrm{O} \rightarrow \mathrm{E} \rightarrow \mathrm{R}$ is not coupled to proton translocation, in contrast to $\mathrm{O}_{\mathrm{H}} \rightarrow \mathrm{E}_{\mathrm{H}} \rightarrow \mathrm{R}$.

Oxygen binds to the BNC only after $\mathrm{R}$ is produced, forming the oxyferrous intermediate $A$, similar to oxyferrous haemoglobin. Breakage of the dioxygen $\mathrm{O}-\mathrm{O}$ bond to form two oxides requires the donation of four electrons. Nevertheless, it occurs within a single rapid step $(A \rightarrow P)$ after oxygen binding. This creates two high potential sites within the $\mathrm{BNC}$, a ferryl haem $a_{3}$ and a radical state of the catalytic tyrosine (YO') that is linked to $\mathrm{Cu}_{\mathrm{B}}{ }^{2+}$. The reaction cycle is completed by two further electron transfers into the $\mathrm{BNC}$ via the $\mathrm{Cu}_{\mathrm{A}} \rightarrow$ haem a route to reduce these two sites: the first electron reduces the $\mathrm{YO}^{\bullet} / \mathrm{Cu}_{\mathrm{B}}{ }^{2+}$ centre, probably forming primarily $\mathrm{YO}^{\bullet} / \mathrm{Cu}_{\mathrm{B}}{ }_{-}{ }_{-}$to produce $\mathrm{F}$ and the second reduces the ferryl haem $a_{3}$ in $\mathrm{F}$ to its ferric form, hence reforming the oxidised $\mathrm{O}_{\mathrm{H}}$ state. $\mathrm{O}_{\mathrm{H}}$ then enters a new catalytic cycle or slowly decays into the nonprotonmotive $\mathrm{O}$ form.

It has been established that there is no net charge change in the stable catalytic intermediates $(36,37)$. This charge neutrality arises from the low dielectric environment of the BNC and is achieved by the uptake of a 
charge-counterbalancing proton from the $\mathrm{N}$ phase $\left(\mathrm{H}_{\mathrm{N}}{ }^{+}\right)$with each of the four electron transfers into the BNC, as shown in figure 4. As also described below, each electron transfer from haem a into the BNC is also coupled to the translocation of one proton from the $\mathrm{N}$ to the $\mathrm{P}$ phase (shown in red in Figure 4 ) in a process in which this charge neutrality feature plays a key role.

Despite the wealth of detailed knowledge, there are still aspects of this complex reaction cycle that are not yet resolved. In particular, the detailed electron and proton distribution in various BNC intermediates, the role(s) of the catalytic tyrosine and the rationale for (and control and gating of) two possible proton pathways into the BNC remain under discussion. Details of both the catalytic intermediates of the reaction cycle and the proposed mechanism of its coupling to the protonmotive reactions are discussed below.

\section{The Catalytic Cycle Intermediates}

Several excellent reviews of the known catalytic intermediates have appeared fairly recently $(24,38)$. Here, the oxidised $\mathrm{O}_{H}$ state refers to an unstable form that is formed during catalysis and that is active in proton translocation. The oxidised $O$ state refers to the isolated, 'fast' form of oxidised $\mathrm{CcO}$ that forms spontaneously from $\mathrm{O}_{\mathrm{H}}$ when catalysis is halted. However, as noted (38), the term 'oxidised' is something of a misnomer since the BNC attains higher oxidation states during catalysis.

For clarity, only the redox changes within the BNC are described below. The other two redox metal sites $\left(\mathrm{Cu}_{\mathrm{A}}\right.$ and haem $\left.\mathrm{a}\right)$ simply cycle between their $\left(\mathrm{Cu}^{1.5+} \mathrm{Cu}^{1.5+}\right) /\left(\mathrm{Cu}^{1+} \mathrm{Cu}^{1+}\right)$ and $\mathrm{Fe}^{2+} / \mathrm{Fe}^{3+}$ forms to deliver electrons from cytochrome $c$ into the $B N C$ at the $\mathrm{O}_{(H)} \rightarrow \mathrm{E}_{(H)}, \mathrm{E}_{(\mathrm{H})} \rightarrow \mathrm{R}, \mathrm{P} \rightarrow \mathrm{F}$ and $\mathrm{F} \rightarrow \mathrm{O}_{(\mathrm{H})}$ steps.

\section{The O (Oxidised) State}

It has long been known that the oxidised form of purified $\mathrm{CcO}$ can exist in a variety of ligation states that can form when the enzyme is not turning over (39). Some of these are caused simply by binding of ligands to haem $a_{3}$, for example chloride or bicarbonate, to give characteristic ligated haem states. Less clear, and still not fully resolved, are forms that do not arise from binding of an external ligand. Two states have been long known but still cause confusion. The so-called 'fast' ('pulsed') form (Soret peak at $424 \mathrm{~nm}$ ) is able to bind external ligands such as cyanide relatively rapidly and displays rapid electron transfer into the 
BNC. In contrast, the 'slow' ('resting') form (Soret peak at 414nm) binds ligands such as cyanide very slowly and has very slow electron transfer into the BNC. Crystallographic and other spectroscopic data have to date failed to chemically define these forms unequivocally. Crystal structures of bovine and $P$. denitrificans CcOs thought to be in the 'fast' form (Soret peak at $424 \mathrm{~nm}$ ) have been modelled with a peroxide bridge between ferric $\left(\mathrm{Fe}^{3+}\right)$ haem $\mathrm{a}_{3}$ and $\mathrm{Cu}_{\mathrm{B}}{ }^{2+}(40,41)$. Some support for this came with the observation that 6 electrons were required to reduce the 'fast' oxidised bovine $\mathrm{CcO}$ (42). However, the same form of $R h$.

sphaeroides $\mathrm{CcO}$ was modelled with two hydroxides (43). More recently, based partly on the observation of X-ray-induced reduction of crystals to form a 590nm species (44), it has been suggested that the observed bridging ligand in all cases might be oxygen or even superoxide (38).

Regardless of these uncertainties most studies suggest that, at least in the 'fast' oxidised $\mathrm{O}$ form of $\mathrm{CcO}$, there should be water or hydroxide ligands on the oxidised forms of both the haem $\mathrm{a}_{3}$ and the $\mathrm{Cu}_{\mathrm{B}}$. In addition, consistent with the electroneutrality of conversions between stable BNC intermediates (45), it has been shown that reduction of the two BNC metals to form $\mathrm{R}$ is associated with the uptake of two chargecounterbalancing protons $(36,37)$. It has generally been assumed that these two protonatable sites must be present within the BNC. Most studies are consistent with a hydroxide on $\mathrm{Cu}_{\mathrm{B}}$ which provides one of these sites. The other site could be either a hydroxide (rather than water ligand) on the haem or a tyrosinate state of the catalytic tyrosine $(46,47)$. This issue is not fully resolved and may even involve the sharing of one proton between the possible sites through $\mathrm{H}$-bonding so that their chemical states cannot be precisely defined.

$$
\text { (' } \mathrm{O}_{\mathrm{H}} \text { ') }
$$

The Catalytically-Active Oxidised State During Turnover

The issue was further complicated with the observation that proton translocation did not occur on reduction of a 'fast' oxidised $\mathrm{CcO}$ that was incorporated into a lipid membrane unless the enzyme was firstly activated by a reduction and reoxidation cycle (48). It was concluded that the active, protonmotive form of oxidised $\mathrm{CcO}$ is likely to be a relatively short-lived state formed during turnover that is different from any of those found in purified enzyme forms that were not turning over. This transient, active form was termed ' $\mathrm{O}$ ' (48) and subsequently ' $\mathrm{O}_{\mathrm{H}}$ ' (49). 
The chemical identity of $\mathrm{O}_{H}$ is not yet clear, though it seems reasonable that the difference should lie within the BNC itself. The difference could explain a thermodynamic problem that arises when considering the free energy changes associated with reduction of the $\mathrm{O}$ state. Specifically, in the 'fast' $O$ form of the enzyme, the measured equilibrium midpoint potentials of haem $a$ and the BNC metals are roughly the same. Hence, when a PMF is present, any coupled proton translocations would make the $\mathrm{O} \rightarrow \mathrm{R}$ conversion highly unfavourable thermodynamically, creating a severe kinetic limitation to the forward reaction. Nevertheless, the twoelectron reduction of the $\mathrm{O}_{\mathrm{H}}$ form into $\mathrm{R}$ is coupled to two proton translocations. Hence, $\mathrm{O}_{H}$ must have a different configuration to the $\mathrm{O}$ state which raises the free energy of the redox reaction sufficiently to support proton translocations at a kinetically-competent rate.

Elegant time-resolved Raman data revealed a transient $450 \mathrm{~cm}^{-1}$ species formed during the $\mathrm{F} \rightarrow \mathrm{O}$ transition that decayed to a more stable $\mathrm{O}$ form. Its frequency suggested a high spin ferric haem $a_{3}$-hydroxide species $(50,51)$. QM calculations indicated that such a species could raise the midpoint potential of $\mathrm{Cu}_{\mathrm{B}}(49)$, as has been observed experimentally. Hence, such a configuration might at least in part address the thermodynamic requirements for reduction of the $\mathrm{O}_{\mathrm{H}}$ state.

Unfortunately, the rapid $(10 \mathrm{msec})$ decay of its signature, which may be caused simply by ${ }^{16} \mathrm{OH}^{-} /{ }^{18} \mathrm{OH}^{-}$exchange, does not provide clear information on its stability (51). However, subsequent QM calculations with a hydroxide ligand bridging the ferric haem iron and $\mathrm{Cu}_{\mathrm{B}}$ have provided further support for this type of structure, with the hydroxide ligand bridging the ferric haem iron and $\mathrm{Cu}_{\mathrm{B}}(49)$. This raises the $\mathrm{Cu}_{B}$ midpoint potential and gives some radical character to the catalytic tyrosine by electron transfer from it towards the $\mathrm{Cu}_{\mathrm{B}}{ }^{2+}$. Other $\mathrm{QM}$ calculations also suggest that $\mathrm{Cu}_{\mathrm{B}}$ has a sufficiently high operative potential that it can receive an electron transfer from the catalytic tyrosine to form $\mathrm{Cu}_{\mathrm{B}}{ }^{+} \ldots \mathrm{Tyr}-\mathrm{O}^{\bullet}$ in $\mathrm{O}_{\mathrm{H}}(52,53)$. Hence, the reduction of such an $\mathrm{O}_{\mathrm{H}}$ configuration by haem a could become sufficiently exergonic to allow kinetically-competent coupled proton translocations in the $\mathrm{O}_{\mathrm{H}} \rightarrow \mathrm{R}$ conversion (54).

\section{States}

The $E$ (Electronated), R (Reduced) and A (Oxyferrous)

The first two steps $\left(\mathrm{O}_{(H)} \rightarrow \mathrm{E}_{(\mathrm{H})}\right.$ and $\left.\mathrm{E}_{(\mathrm{H})} \rightarrow \mathrm{R}\right)$ involve donation of an electron from the low spin haem into the BNC, with each associated with charge compensating protonation (with $\mathrm{N}$ phase protons) of one of the available $\mathrm{BNC}$ protonation sites. In the case of $\mathrm{O} \rightarrow \mathrm{E} \rightarrow \mathrm{R}$, the most likely 
scenario is that $\mathrm{Cu}_{\mathrm{B}}{ }^{2+}$ becomes reduced in the $\mathrm{O} \rightarrow \mathrm{E}$ transition and this causes protonation of its hydroxide and water release. In $\mathrm{E} \rightarrow \mathrm{R}$, haem $a_{3}{ }^{3+}$ is reduced to its ferrous state; its water ligand is released and the net proton uptake leaves tyrosine in its protonated state. There is still discussion regarding the electronic and protonation patterns in the $\mathrm{O}_{\mathrm{H}}$ and $E_{H}$ configurations. In Figure 5, the first electron and proton transfer to form $\mathrm{E}_{\mathrm{H}}$ is shown as reducing and protonating either $\mathrm{Cu}_{\mathrm{B}}{ }^{+} \ldots \mathrm{Tyr}-\mathrm{O}^{\bullet}$ to $\mathrm{Cu}_{\mathrm{B}}{ }^{+} \ldots$ TyrOH or $\mathrm{a}_{3}{ }^{3+}-\mathrm{OH}^{-}$to $\mathrm{a}_{3}{ }^{2+}-\mathrm{H}_{2} \mathrm{O}$, as suggested by QM calculations $(52,53)$.

Regardless of these possible proposed configurations of $\mathrm{O}_{(\mathrm{H})}$ and $\mathrm{E}_{(\mathrm{H})}$, the two reduction steps result in formation of intermediate $\mathrm{R}$, with a BNC configuration of $\mathrm{Fe}^{2+} \ldots \mathrm{Cu}_{\mathrm{B}}{ }^{1+}$ and the catalytic tyrosine protonated as Tyr$\mathrm{OH}$. Any ligands on the metals have become protonated to form free water molecules which move away from the metals. Hence, at this R stage the BNC metals have free coordination sites, removing any steric hindrance to dioxygen binding between the metals. Dioxygen binds to the haem $\mathrm{a}_{3}{ }^{2+}$, with little or no electronic interaction with $\mathrm{Cu}_{\mathrm{B}}{ }^{+}(24)$ to form a very unstable oxyferrous intermediate termed $A$. This species was first detected by Chance from its characteristic visible absorption band in his low temperature 'triple-trapping' pioneering work (55). It is likely to have a predominantly ferric -superoxide rather than ferrousoxygen structure (24).

\section{The 607nm P ('Peroxy') State}

At room temperature, and if an electron is not already present on haem $a$, intermediate A decays in $\sim 300 \mu s e c$ into intermediate $P$ of Figure 4 , which is characterised by a visible $\alpha$-band at $607 \mathrm{~nm}$. The ' $P$ ' label arose from the initial suggestion that it was a peroxide intermediate. However, it is now clear from Raman work $(50,56)$ that the $0-O$ bond has been cleaved, as had been suggested earlier from iodination studies (57). This means that dioxygen has received four electrons and split into two oxide dianion products. This is achieved with one electron from $\mathrm{Cu}_{\mathrm{B}}$ (which becomes cupric - $\mathrm{Cu}^{2+}$ ), one from the catalytic tyrosine (which forms a radical) and two from the ferrous haem $a_{3}$ which, by ligation of one of the oxide dianion products, forms a high oxidation state ferryl $\left(\mathrm{Fe}^{4+}=\mathrm{O}^{2-}\right)$ species. Oxidation of the catalytic tyrosine lowers its $\mathrm{pK}$, releasing its proton and forming a neutral radical $\left(\mathrm{Tyr}-\mathrm{O}^{\bullet}\right)$. The proton is retained within the $\mathrm{BNC}$, most likely protonating the second oxide product to provide a hydroxide ligand to $\mathrm{Cu}_{\mathrm{B}}{ }^{2+}(52,58)$. 
No partially-reduced oxygen intermediates in this four electron process have been detected. This has the advantage that there is no possibility that such potentially damaging free reactive oxygen species (ROS) (59) could leak from the site.

\section{The 580nm F (Ferryl) and 607nm $P_{R}$ Intermediates}

The next step in the cycle is the transfer of a further electron into the $\mathrm{BNC}$ from the low spin haem. It seems likely that this should reduce the highly oxidizing tyrosine radical back to its tyrosinate state. However, as with every electron transfer into the BNC, this is coupled with a chargecompensating proton uptake from the $\mathrm{N}$ phase. This could reprotonate the tyrosinate, though FTIR data argue against this (60). Indeed, recent QM calculations suggest instead that it protonates the hydroxide ligand of $\mathrm{Cu}_{\mathrm{B}}{ }^{2+}$ into a water, which is again coupled with electron redistribution from tyrosinate to $\mathrm{Cu}_{\mathrm{B}}$ to create $\mathrm{H}_{2} \mathrm{O}-\mathrm{Cu}_{\mathrm{B}}{ }^{1+} \ldots$ Tyr-O ${ }^{\circ}$ centre in $\mathrm{F}$. In any case, haem $a_{3}$ remains in its ferryl state, as confirmed by its Soret band position and Raman Fe-O stretch frequency $(61,62)$, but now with an $\alpha-$ band at $580 \mathrm{~nm}$.

In flow-flash experiments in which the catalytic cycle is initiated by photolysis of $\mathrm{CO}$ from the fully reduced $\mathrm{CcO}$ (i.e. with all four metal sites reduced) in the presence of oxygen (63), electrons are already available on $\mathrm{Cu}_{\mathrm{A}}{ }^{+} /$haem $\mathrm{a}^{2+}$ whilst compound $\mathrm{A}$ is decaying into its product.

Electron transfer is sufficiently rapid that, at least in bovine $\mathrm{C} C \mathrm{O}$, electron transfer from haem $a^{2+}$ is synchronous with compound $A$ transformation such that the immediate product has one more electron than the P state $(64,65)$. This intermediate has been termed $P_{R}$. Subsequent protonation of $P_{R}$ results in the same $F$ state. Formation of $P_{R}$ is significantly faster than formation of $P$ and so is likely to be a direct product from $A$, rather than forming via the $P$ intermediate (65), as shown in Figure 4. This is consistent with the observation, at least when initiating the sequence with fully reduced bovine $\mathrm{CcO}$, that $\mathrm{P}_{\mathrm{R}}$ is the main kinetic intermediate observed between A and F. Interestingly, the visible absorption band of $P_{R}$ is at the same $607 \mathrm{~nm}$ as that of the $P$ state above, despite the fact that it is isoelectronic with $\mathrm{F}$. Only when the proton binds subsequently to $P_{R}$ does it shift to the $580 \mathrm{~nm}$ that is characteristic of the $F$ state. This absorption band arises from ferryl haem $a_{3}$ and its wavelength position can be governed by the strength of $\mathrm{H}$-bonding to its oxide ligand, which may increase only when the proton is binds to $P_{R}$ to form $F(38)$. 
Finally, one further (fourth) electron transfer reduces the ferryl haem $a_{3}$ in $\mathrm{F}$ back to its ferric state. Again this electron transfer into the BNC induces uptake of an $\mathrm{N}$ phase proton for charge compensation. The most likely scenario is that the oxide ligand is protonated to a hydroxide, which remains ligated to the now ferric haem $a_{3}$. Hence, in comparison to the starting oxidised state, four electrons and four protons have been taken up and dioxygen has been converted into two water molecules. The ligation configuration of the resulting ' $\mathrm{O}_{\mathrm{H}}$ ' state is formed. In Figure 5 this is shown, as suggested $(52,58)$, as a hydroxide ligand on ferric haem $\mathrm{a}_{3}$ which bridges to $\mathrm{Cu}_{\mathrm{B}}$.

\section{Alternative Models of the Catalytic Cycle}

Despite reasonable spectroscopic and kinetic evidence for many aspects of the above mechanism, and the feasible chemistry that it entails, this cycle is not universally agreed. As discussed above, uncertainty remains in particular in the structure of the catalytically active $\mathrm{O}_{\mathrm{H}}$ state and its reduction to the oxygen-binding $\mathrm{R}$ intermediate, with further variations suggested that are based on a peroxide structure that had been suggested from crystallographic analyses $(40,41)$.

More recently, a challenge has come also from considerations of primarily crystallographic information and an alternative coupling mechanism (24). It has been suggested that the experimentallymeasured net proton uptakes associated with each electron transfer into the BNC may not bind within the BNC as described above. Instead (Figure 7), it is proposed that the two net proton uptakes associated with the $\mathrm{O} \rightarrow \mathrm{R}$ step can be accounted for by release of two protons from a proton trap site into the $\mathrm{P}$ phase in the $\mathrm{O} \rightarrow \mathrm{R}$ steps, followed by the uptake of four $N$ phase protons after $R$ is formed (shown as an $R_{1} \rightarrow R_{2}$ step in Figure 6). Only when $R_{2}$ is formed can oxygen bind to ferrous haem $a_{3}$ to form the $A$ intermediate These four protons are proposed to be bound in a proton trap region around the $\mathrm{Mg}^{2+}$, after which they are sequentially released into the $P$ phase, one with each redox cycle of haem a (66). To accommodate this, the substrate protons required for the oxygen reduction chemistry must be bound into the BNC only in $\mathrm{P} \rightarrow \mathrm{F}$ and $\mathrm{F} \rightarrow \mathrm{O}$ (two in each step). Further details and caveats are provided below. Clearly, if correct, the detailed chemistry described above would have to be significantly re-evaluated. Further spectroscopic analyses will be needed to test and resolve such possibilities.

\section{Coupled Proton Translocation}




\section{Structural aspects of proton translocation}

The core structure of CcOs must have domains that can transfer protons into and across the hydrophobic interior both for oxygen reduction and for proton translocation. In the tightly packed interior of subunit I, these will consist of arrays of hydrophilic amino acids and water molecules that can, at least transiently, form an H-bonded 'proton wire' $(67,68)$ that connects to an aqueous phase and allows proton transfer by a Grotthuss-type of mechanism (69). Several such arrays were revealed in the crystal structures of both A-type bacterial (22) and bovine mitochondrial $\mathrm{CcO}(70)$ structures (Figure 3). The K channel, named from a lysine (K319) in its centre, connects the $\mathrm{N}$ aqueous phase to the catalytic tyrosine of the BNC. A second array, the $D$ channel, leads from an aspartic acid (D91) at its $N$ phase entrance to a glutamic acid (A1type) or a tyrosine (A2-type) that is located roughly equidistant from the two haem edges.

A third somewhat more complex structure, termed the $\mathrm{H}$ channel, was firstly described in the bovine $\mathrm{CcO}$ structure (24), though many of its proposed components are also present in bacterial A-type CcOs. It consists of two principal domains that are linked via the D-ring formyl and propionate groups of haem a. The longer 'lower' domain connects this linking region to the $\mathrm{N}$ phase and consists of several hydrophilic amino acids together with a series of hydratable cavities, at least one of which is opened only transiently during turnover. The 'upper' region consists of a network of hydrophilic amino acids and waters that connect to the $\mathrm{P}$ phase at residue D51, an aspartic acid whose conformation is redox-dependent. It is proposed that proton transfer from the linker region to this domain is through the peptide link between Y440 and S441, which can act as a unidirectional proton gate.

All proposed mechanisms of proton translocation in the A-type CcOs have several features in common. The first is that all four proton translocations occur by essentially the same mechanism, with one proton translocation linked to each of the four steps of electron transfer from haem a into the BNC, regardless of the stage of the oxygen reduction cycle $(48,71,72)$. A second common consideration is a means whereby proton transfers are 'gated' so that transfer against a PMF still occurs without uncoupling. However, the specific roles of the $\mathrm{K}, \mathrm{D}$ and $\mathrm{H}$ channels in conducting protons, particularly the translocated protons, are presently disputed. In particular, studies of mutant forms of bacterial Atype CcOs with a wide range of time resolved methods that measure spectra, electrometric changes and $\mathrm{pH}$ changes have led to a 
consensus model involving only the $\mathrm{D}$ and $\mathrm{K}$ channels, with no clear role for the $\mathrm{H}$ channel (73). In contrast, deductions from the atomic structure of bovine $\mathrm{CcO}$, together with more limited direct functional measurements, have indicated a central role of the $\mathrm{H}$ pathway in proton translocation with the $\mathrm{D}$ and/or $\mathrm{K}$ channels providing possible routes only for substrate protons (24).

Below, I critically discuss the coupling mechanism that is supported in particular by a large body of data from studies of bacterial A-type CcOs. This is followed by a summary of the proposed model of coupling in mammalian forms of $\mathrm{CcO}$.

\section{A general coupling mechanism in A1-type CcOs}

Studies with bacterial $\mathrm{CcO}$ mutants have convincingly shown the importance of the $\mathrm{D}$ and $\mathrm{K}$ channels for proton transfer processes, whilst mutations of residues in the $\mathrm{H}$ channel region (74) have not yet revealed any functional importance. Specifically, mutations in the $\mathrm{K}$ channel are without significant effect on $\mathrm{P} \rightarrow \mathrm{F} \rightarrow \mathrm{O}$ steps of the catalytic cycle or their associated proton translocations whereas mutations in the $D$ channel can strongly affect them. In contrast, both $\mathrm{K}$ and $\mathrm{D}$ channel mutations can affect the $\mathrm{O} \rightarrow \mathrm{E} \rightarrow \mathrm{R}$ steps $(75,76)$. Most significantly, some mutations in the $\mathrm{D}$ channel can prevent proton translocation without inhibiting the oxygen chemistry $(77,78)$. From this it has been concluded that the K pathway provides the route for one or both substrate protons and that the $\mathrm{D}$ channel provides the path for the remaining 2-3 substrate protons and all four translocated protons (79).

As noted above, one proton translocation is associated with each of the four steps of electron transfer from the low spin haem into the BNC $\left(\mathrm{O}_{\mathrm{H}} \rightarrow \mathrm{E}_{\mathrm{H}}, \mathrm{E}_{\mathrm{H}} \rightarrow \mathrm{R}, \mathrm{P} \rightarrow \mathrm{F}\right.$ and $\left.\mathrm{F} \rightarrow \mathrm{O}\right)$ and all four of these coupled proton transfers are thought to share the same mechanism. Also inherent in this mechanism is the assumption that the four net proton uptakes that are associated with the charge-counterbalancing of the four steps of BNC reduction (45) are substrate protons that bind within the BNC, rather than being associated with the proton translocating pathway (this is a major difference with the alternative model for mammalian $\mathrm{CcO}$ s that is summarised below).

The coupling sequence description in Figure 6 begins with an oxidised low spin haem a. At this stage, consistent with FTIR data (80), residue E242 at the top of the D channel is protonated. Electron transfer into the haem $a$ and from there to the BNC is associated with pK changes that 
cause the glutamic acid proton to move towards a 'trap' site located above the BNC. This trap site has not been identified experimentally, but the general consensus is that it involves the protonatable amino acids and water molecules close to the bound $\mathrm{Mg}^{2+}$ ion' above the BNC. Quite possibly, the proton is shared between several groups in this region (81), lowering its energy and perhaps explaining its lack of experimental detection. The positively-charged trap site electrostatically lowers the energy required to transfer the negative electron into the $\mathrm{BNC}$, but is positioned such that the proton cannot act as a substrate proton for subsequent water formation. It may well be that full transfer of the electron into the BNC causes further movement of the 'trap' proton away from the pathway from E242, hence contributing to means of prevention of subsequent backflow. Since the movement of the proton and the electron are presumably temporally separated, the K channel may provide an additional role as a 'dielectric channel' in this PCET process (82). This could lower the energetics of any transient charged BNC intermediate by reversible movement of charge within the $\mathrm{K}$ channel (perhaps involving the protonated $\mathrm{K} 319$ residue $(73,83,84)$ ). This might be particularly relevant in the $\mathrm{O}_{\mathrm{H}} \rightarrow \mathrm{E}_{\mathrm{H}} \rightarrow \mathrm{R}$ steps which may not have a large driving force.

Once this coupled step is completed, the glutamate becomes reprotonated from the $\mathrm{N}$ phase (via the $\mathrm{D}$ channel) because the haem a is again in its ferric form and the pK of E242 has returned to that of the starting state. However, the arrival of the electron within the BNC results in progression of the oxygen reduction cycle, which creates a low pK site that requires a substrate proton to be bound. The current consensus view, based on the effects of mutations in the channels, is that the first, and possibly the second, substrate protons (i.e. those linked to the $\mathrm{O}_{\mathrm{H}} \rightarrow \mathrm{E}_{\mathrm{H}} \rightarrow \mathrm{R}$ steps) arrive through the $\mathrm{K}$ channel and the others arrive through the D channel and E242. In this latter case, a proton pathway between E242 and the BNC must be formed, whilst blocking any return path for the trap proton i.e. to avoid uncoupling the E242/trap route must be strictly gated in concert with pK changes. Plausible mechanisms involving transient formation of $\mathrm{H}$-bonded water arrays and gating principles have been proposed (85-87).

The arrival of the electron and the substrate proton into the BNC results in transformation to the next stable oxygen intermediate and the E242 again reprotonates from the $\mathrm{N}$ phase via the $\mathrm{D}$ channel. Since the change within the BNC is now electroneutral, the stabilization of the positive charge in the trap site by the BNC negative charge is lost. Hence, the pK of the trap decreasesrises and the proton is lost, in this 
case through a path into the $\mathrm{P}$ phase since it no longer has a connection into the $\mathrm{D}$ channel. Again, it is necessary that this trap/P phase pathway is gated in some manner so that electron transfer into the BNC is not charge-compensated by trap protonation from the $\mathrm{P}$ phase.

\section{Outstanding issues}

The above outline describes a feasible coupling mechanism involving the $\mathrm{D}$ and $\mathrm{K}$ channels that is supported by a considerable body of experimental data, particularly from bacterial A1-type $\mathrm{CcO}$ studies. However, issues remain that are yet to be fully resolved. One is the mechanism and functional significance of the partitioning of substrate proton entry into the BNC between the K and D channels. Recently, both a mechanistic basis (58) and a functional rationale in terms of a need to control formation of appropriate protonation configurations with energetics sufficient to drive proton translocation (52) was suggested, based on QM simulations. A further issue is the temporal order of the proton and electron transfer steps outlined above; clearly, protonation of the trap site has to precede that of the binuclear centre (but see (72)). This is perhaps explained by the progression of pK changes. However, the detailed order of the other electron and proton transfer steps still requires further definition and understanding. Also outstanding is the possible additional function of the $\mathrm{K}$ channel as a dielectric channel in some of the reaction steps (82) as well as the nature of the proton trap site which has to date defied experimental identification, though again simulations have provided support for its location around the $\mathrm{Mg}^{++}$site (81).

Perhaps most difficult to understand is how the observable D channel and E242, the trap site and the exit route from the trap to the $P$ phase can provide the necessary temporal gating that is required to connect to the $\mathrm{N}$ or $\mathrm{P}$ phases and to deliver protons either to the trap site or to the BNC at specific stages of the coupling sequence. These questions are exacerbated by the fact that the crystal structures show no obvious protonic connectivity between E242 and the region above the BNC. Gating is required both to prevent protonation of the trap from the $P$ phase and to prevent the trap proton from travelling back through E242 and into the BNC; in both cases, such reactions would result in uncoupling. In general terms, this gating must be achieved by proton transfers (trap $\rightarrow$ P phase; E242 $\rightarrow$ trap; E242 $\rightarrow$ BNC) whose pathways are formed only transiently at the required steps so that any reverse proton flow is prevented. Presumably, this occurs through chemicallyand electrostatically-controlled changes of $\mathrm{H}$-bonding networks and $\mathrm{pKs}$. 
MM/QM simulations have provided a viable model for proton transfer from E242 to the trap or to the BNC involving a charged intermediate (88) and/or the transient formation of $\mathrm{H}$-bonded water chains $(85-87,89)$. FTIR studies have provided evidence for such water molecule reorganisation, though their locations and temporal nature have not yet been determined (90).

\section{translocation \\ Alternative models of mechanism of proton}

$\mathrm{HCO}$ in the $\mathrm{B}$ and $\mathrm{C}$ subclasses of the superfamily do not possess a functional $\mathrm{D}$ channel and yet are coupled to proton translocation, though at a lower stoichiometry (91) or, possibly, less tightly coupled (4). They have a channel related to the $\mathrm{K}$ channel, though whether they possess a second functional channel of some type is not clear. These findings have led to the notion that, although the catalytic mechanism of oxygen reduction is likely to be very similar in all $\mathrm{HCOs}$, the mechanisms of coupling to proton translocation may be more varied and achievable by different types of structures.

The notion of alternative coupling mechanisms within the A1-type HCOs has also arisen, prompted by the atomic structure of bovine mitochondrial $\mathrm{C} C \mathrm{O}$ which revealed a third hydrophilic domain within subunit I, the $\mathrm{H}$ channel (92). As described above, this structure consists of a series of potentially hydratable cavities leading from the $\mathrm{N}$ phase to haem $a$, and from there to the $\mathrm{P}$ phase via a peptide gate to an $\mathrm{H}$ bonded network of amino acids and fixed waters. Comparisons of oxidised, reduced and ligated structures have led to a model in which opening of the water channel occurs only at the $\mathrm{R}$ stage of the catalytic cycle (72), driven by conformational changes that induce residue S382 to move out of, and hence open, the largest of the water cavities. This is followed by the uptake of four protons into the equivalent of a trap site. Protons are proposed to then be released sequentially into the $\mathrm{P}$ phase, one with each redox cycle of haem a $(24,93)$. Most recently, because there is insufficient proton binding capacity around haem $a$, it was proposed that the trap site for these four protons is located around the $\mathrm{Mg}^{2+}(66)$. Connection to the $\mathrm{P}$ phase was proposed to be controlled by redox cycling of haem $a$, with the route involving elements described in earlier models of the $\mathrm{H}$-bonded network above haem $\mathrm{a}$ and gated by the peptide bond between Y440/S441 (66).

This mechanism differs from that deduced from bacterial studies in two key ways. The first of these is in the pathway taken by the translocated 
protons. Some direct experimental evidence that both the lower and upper domains of the $\mathrm{H}$ channel fulfill this role has come from mutation studies using a hybrid bovine/human construct. These studies indicated that such mutations cause loss of coupled proton translocation without affecting catalytic oxygen reduction rates (94). Measurements of this kind are not without caveats of interpretation and the fact that none caused an associated inhibition of oxygen reduction requires explanation. Furthermore, studies of mutants of the closely related yeast (S. cerevisiae) $\mathrm{CcO}$, which also has an $\mathrm{H}$ channel structure, albeit with significant differences to the bovine structure, do not result in the same uncoupling. Indeed, mutations in its $D$ and $K$ channels appear to behave in a manner similar to mutations in these channels in the bacterial CcOs $(95,96)$.

A second key way in which this mechanism differs is in the interpretation of which stages of the catalytic cycle are linked to substrate and translocated proton movements. Since all four translocated protons are bound at a single step (after $\mathrm{R}$ formation, Figure 7), the steps at which substrate protons are bound has to also be revised. Specifically, in order to accommodate the net proton uptakes at each step of BNC reduction $(36,37)$, the four substrate protons would have to be bound in the $P \rightarrow F$ and $\mathrm{F} \rightarrow \mathrm{O}$ steps (with the two net protonations in the $\underline{\mathrm{O}} \mathrm{E} \rightarrow \mathrm{R}$ stage caused by two protons released from, and four protons rebound into, the trap site). Although consistent with the some of the experimentally measured net proton uptakes of only one per BNC reduction step, it predicts that full reduction of the non-protonmotive $O$ state should result in four protons taken up plus any associated with haem $\mathrm{a} / \mathrm{Cu}_{\mathrm{A}}$ reduction, which is clearly not the case (37). Furthermore, though generally consistent with overall electrogenicity of the $\mathrm{P} \rightarrow \mathrm{F} \rightarrow \mathrm{O}$ steps, it would require modification to accommodate electrometric data on the $\mathrm{O}_{\mathrm{H}} \rightarrow \mathrm{E}_{\mathrm{H}}$ transition $(97,98)$ which clearly indicate two net charge translocations in a sequence along the lines of that summarised in Figure 6. It would also imply an extreme $\mathrm{pH}$-dependency of the rate of binding of oxygen to haem $a_{3}$ after the initial $R_{1}$ state has formed since four proton transfers would be required before oxygen could bind.

Further direct experimental data, perhaps aimed at the features summarised above, will be required to further test this model. Perhaps most importantly, the scheme implies that charge neutralisation of stable BNC states does not occur by protonations within the BNC itself. Hence, major revision would be required of the chemical nature of the stable oxygen intermediates and the forces that drive proton translocation. It also appears that the mechanism might apply only to forms of $\mathrm{CcO}$ that 
are close to mammalian forms since key features of the $\mathrm{H}$ channel are not well-conserved in many other eukaryotes and, in the case of yeast $\mathrm{CcO}$, direct experiments have argued against such a role. Other experiments have also led to the suggestion that the $\mathrm{H}$ channel and its varying structure in other A-type $\mathrm{CcOs}$ might play a more universal role as a dielectric channel, influencing the properties of haem a for optimal performance and possibly enzymatic control (82). Interestingly the A1type quinol oxidase do not possess an equivalent $\mathrm{H}$ channel (73); however, in this case, electron transfer to the low spin haem occurs from neutral ubiquinol in the membrane domain and, instead, a proton channel is present to conduct the released protons into the $\mathrm{P}$ phase after charge separation. Whether a dielectric role of the $\mathrm{H}$ channel applies in addition to, or instead of, a proton translocating role in mammalian and related $\mathrm{CcOs}$ remains to be examined experimentally.

\section{Concluding Remarks}

There has been tremendous progress in unravelling the intricate interlinked core functions of electron transfer, oxygen reduction chemistry and the coupled mechanism of energy-conserving proton translocations in the A-type $\mathrm{HCOs}$, of which mitochondrial $\mathrm{CcO}$ is a particularly well-studied member. The obligatory pathway of electron transfer through the low spin haem into the catalytic BNC is wellestablished experimentally, though the precise means by which direct electron transfer to the $\mathrm{BNC}$ from the $\mathrm{Cu}_{\mathrm{A}}$ site is prevented is still not precisely understood. This pathway through the low spin haem appears to be a crucial feature by which the redox reactions are coupled to proton pumping, probably extending to the presently unknown coupling mechanisms in the homologous B- and C-type oxidases.

The intermediates and catalytic cycle of oxygen reduction, again probably occurring by a common mechanism throughout all HCO types, are also fairly well-established particularly in terms of involvement of high potential haem species and of a catalytic tyrosine residue that can act as an electron and proton donor in concert with the metal centre redox changes. These concerted oxidations take place in a single $(\mathrm{R} \rightarrow \mathrm{P})$ step, reducing dioxygen to two oxides in a four electron redox process that has proved impossible to kinetically separate into further intermediate redox steps. The result of this remarkable reaction is that no potentially damaging, partly-reduced reactive oxygen species (usually abbreviated as ROS) are formed, making $\mathrm{CcO}$ the least of the major respiratory complexes to contribute to mitochondrial ROS production. Nevertheless, as shown in figure 4, the catalytic tyrosine itself is thought 
to form a radical state and questions still remain as to whether this is itself stable or perhaps can migrate to other amino acids. Still particularly contentious is the nature of the BNC chemistry in the steps of reduction of the oxidised state into the oxygen-binding $R$ state. As discussed above, reduction of forms of the enzyme after purification appear to be unable to provide sufficient free energy for associated proton transfers, as has been confirmed experimentally. Instead current opinion is that a transient and unstable form of the oxidised form, termed $\mathrm{O}_{\mathrm{H}}$, is formed during catalysis. This form must differ in configuration and energetics of the BNC such that sufficient free energy is available on reduction to $R$ for coupled proton transfers. The exact nature of this $\mathrm{O}_{H}\left(\right.$ and $\left.\mathrm{E}_{H}\right)$ state has defied experimental identification to date, though several QM/MMderived models of likely structure have been proposed. To date, all models have assumed that the differences between $O / O_{H}$ and $E / E_{H}$ reside within the $\mathrm{BNC}$ itself. The type of model proposed for $\mathrm{H}$ channel function, in which net proton uptakes are not necessarily all within the $\mathrm{BNC}$, does raise an interesting consideration that perhaps some differences arise in protonation pattern differences of the activated states involving the trap site(s). Such electrostatically-locked states (45) might decay to the non-protonmotive forms by protonic exchange into the BNC.

There is consensus in the field that the four proton translocations are associated with each of the four catalytic steps of electron transfer from the low spin haem into the BNC. All are likely to occur by the same basic mechanism and electrostatic considerations are a central feature of the chemical mechanism of action. Bacterial studies have led to a convincing mechanism involving the $D$ channel, though questions remain as to how its transient connectivities are made and robustly gated to ensure efficient coupling. Structural data on bovine mitochondrial $\mathrm{CcO}$ have raised the question of whether the $\mathrm{D}$ channel coupling mechanism has been replaced in closely related $\mathrm{CcOs}$ by one involving the separate $\mathrm{H}$ channel structure. This mechanism will require further experimental investigation, as do the mechanisms of coupling in $\mathrm{B}$ and $\mathrm{C}$-type HCOs which lack a functional D channel. Particularly intriguing in the $\mathrm{H}$ channel model is the reinterpretation of the distribution of uptake and release of substrate and translocated protons within the catalytic cycle - such differences may well provide a means to definitively test such variations in coupling models in the future.

\section{Acknowledgements}


I would like to thank Professors Mårten Wikström, Shinya Yoshikawa and Margareta Blomberg and Drs. Amandine Maréchal and Andrew Hartley for useful discussions and/or comments on the manuscript.

\section{Declarations of interest}

The author declares that there are no competing interests associated with the manuscript.

\section{Funding information}

Peter Rich is funded by the BBSRC with grants BB/K001094/1 and $\mathrm{BB} / \mathrm{L} 020165 / 1$ that are directly relevant to this topic.

\section{Author contribution statement}

This article was written entirely by PRR.

\section{References}

1. Mitchell, P. (1966) Chemiosmotic coupling in oxidative and photosynthetic phosphorylation. Glynn Research Ltd, Bodmin.

2. Wikström, M.K.F. (1977) Proton pump coupled to cytochrome $c$ oxidase in mitochondria, Nature 266, 271-273.

3. García-Horsman, J.A., Barquera, B., Rumbley, J., Ma, J., and Gennis, R.B. (1994) The superfamily of heme-copper oxidases, J. Bacteriol. 176, 5587-5600.

4. Sousa, F.L., Alves, R.J., Ribeiro, M.A., Pereira-Leal, J.B., Teixeira, M., and Pereira, M.M. (2012) The superfamily of heme-copper oxygen reductases: types and evolutionary considerations, Biochim. Biophys. Acta Bioenergetics 1817, 629-637.

5. Hemp, J. and Gennis, R. B. (2008)Diversity of the Heme-Copper Superfamily in Archaea: Insights from Genomics and Structural Modeling in Results Probl. Cell. Differ. (Schäfer, G. and Penefsky, H. S., Eds.) Chapter 45, pp 1-31, Springer-Verlag, Berlin, Heidelberg.

6. Tsukihara, T., Aoyama, H., Yamashita, E., Tomizaki, T., Yamaguchi, H., Shinzawa-Itoh, K., Nakashima, R., Yaono, R., and Yoshikawa, S. (1996) The whole structure of the 13-subunit oxidized cytochrome $c$ oxidase at $2.8 \AA$, Science $272,1136-1144$. 
7. Iwata, S., Ostermeier, C., Ludwig, B., and Michel, H. (1995) Structure at $2.8 \AA$ resolution of cytochrome $c$ oxidase from Paracoccus denitrificans, Nature 376, 660-669.

8. Svensson-Ek, M., Abramson, J., Larsson, G., Törnroth, S., Brzezinski, P., and Iwata, S. (2002) The X-ray crystal structures of wild-type and $E Q(I-286)$ mutant cytochrome $c$ oxidases from Rhodobacter sphaeroides, J. Mol. Biol. 321, 329-339.

9. Abramson, J., Riistama, S., Larrson, G., Jasaitis, A., Svensson-Ek, M., Laakkonen, L., Puustinen, A., Iwata, S., and Wikström, M. (2000) The structure of the ubiquinol oxidase from Escherichia coli and its ubiquinone binding site, Nat. Struct. Biol. 7, 910-917.

10. Lyons, J.A., Aragão, D., Slattery, O., Pisliakov, A.V., Soulimane, T., and Caffrey, M. (2012) Structural insigths into electron transfer in caa $_{3}$-type cytochrome oxidase, Nature 487, 514-518.

11. Hemp, J., Christian, C., Barquera, B., Gennis, R.B., and Martínez, T.J. (2005) Helix Switching of a Key Active-Site Residue in the Cytochrome $c b b_{3}$ Oxidases, Biochemistry 44, 10766-10775.

12. Pereira, M.M., Sousa, F.L., Teixeira, M., Nyquist, R.M., and Heberle, J. (2006) A tyrosine residue deprotonates during oxygen reduction by the $\mathrm{Caa}_{3}$ reductase from Rhodothermus marinus, FEBS Lett. 580, 1350-1354.

13. Soulimane, T., Buse, G., Bourenkov, G.P., Bartunik, H.D., Huber, R., and Than, M.E. (2000) Structure and mechanism of the aberrant $b a_{3}$-cytochrome $c$ oxidase from Thermus thermophilus, EMBO J. 19, 1766-1776.

14. Tiefenbrun, T., Liu, W., Chen, Y., Katritch, V., Stout, C.D., Fee, J.A., and Cherezov, V. (2011) High Resolution Structure of the ba3 Cytochrome $c$ Oxidase from Thermus thermophilus in a Lipidic Environment, PLoS One 6, e22348.

15. Buschmann, S., Warkentin, E., Xie, H., Langer, J.D., Ermler, U., and Michel, H. (2010) The structure of $c b b_{3}$ cytochrome oxidase provides insights into proton pumping, Science 329, 327-330.

16. van der Oost, J., De Boer, A.P.N., De Gier, J.-W.L., Zumft, W.G., Stouthamer, A.H., and van Spanning, R.J.M. (1994) The hemecopper oxidase family consists of three distinct types of terminal 
oxidases and is related to nitric oxide reductase, FEMS Microbiol. Lett. 121, 1-10.

17. Reimann, J., Flock, U., Lepp, H., Honigmann, A., and Adelroth, P. (2007) A pathway for protons in nitric oxide reductase from Paracoccus denitrificans., Biochim. Biophys. Acta Bioenergetics $1767,362-373$.

18. Shinzawa-Itoh, K., Aoyama, H., Muramoto, K., Terada, H., Kurauchi, T., Tadehara, Y., Yamasaki, A., Sugimura, T., Kurono, S., Tsujimoto, K., Mizushima, T., Yamashita, E., Tsukihara, T., and Yoshikawa, S. (2007) Structures and physiological roles of 13 integral lipids of bovine heart cytochrome $c$ oxidase, EMBO J. 26, 1713-1725.

19. Hosler, J.P. (2004) The influence of subunit III of cytochrome $c$ oxidase on the $\mathrm{D}$ pathway, the proton exit pathway and mechanism-based inactivation in subunit I, Biochim. Biophys. Acta Bioenergetics 1655, 332-339.

20. Alnajjar, K.S., Hosler, J., and Prochaska, L. (2014) Role of the NTerminus of Subunit III in Proton Uptake in Cytochrome $c$ Oxidase of Rhodobacter sphaeroides, Biochemistry 53, 496-504.

21. Hiser, C., Buhrow, L., Liu, J., Kuhn, L., and Ferguson-Miller, S. (2013) A Conserved Amphipathic Ligand Binding Region Influences K.Path-Dependent Activity of Cytochrome $c$ Oxidase, Biochemistry 52, 1385-1396.

22. Fetter, J.R., Qian, J., Shapleigh, J., Thomas, J.W., GarcíaHorsman, A., Schmidt, E., Hosler, J., Babcock, G.T., Gennis, R.B., and Ferguson-Miller, S. (1995) Possible proton relay pathways in cytochrome $c$ oxidase, Proc. Natl. Acad. Sci. USA 92, 1604-1608.

23. Kaila, V.R.I., Verkhovsky, M.I., and Wikström, M. (2010) Protoncoupled electron transfer in cytochrome oxidase, Chem. Rev. 110, 7062-7081.

24. Yoshikawa, S., and Shimada, A. (2015) Reaction Mechanism of Cytochrome c Oxidase, Chem. Rev. 115, 1936-1989.

25. Alge, D., Wastyn, M., Mayer, C., Jungwirth, C., Zimmermann, U., Zoder, R., Fromwald, S., and Peschek, G.A. (1999) Allosteric Properties of Cyanobacterial Cytochrome $c$ Oxidase: Inhibition of 
the Coupled Enzyme by ATP and Stimulation by ADP, IUBMB Life 48, 187-197.

26. Kadenbach, B., and Hüttemann, M. (2015) The subunit composition and function of mammalian cytochrome $c$ oxidase, Mitochondrion 24, 64-76.

27. Wittig, I., and Schägger, H. (2009) Supramolecular organization of ATP synthase and respiratory chain in mitochondrial membranes, Biochim. Biophys. Acta. 1787, 672-680.

28. Stuart, R.A. (2008) Supercomplex organisation of the oxidative phosphorylation enzymes in yeast mitochondria, J. Bioenerg. Biomemb. 40, 411-417.

29. Dudkina, N.V., Sunderhaus, S., Boekema, E.J., and Braun, H.-P. (2008) The higher level of organization of the oxidative phosphorylation system: mitochondrial supercomplexes, $\mathrm{J}$. Bioenerg. Biomemb. 40, 419-424.

30. Schägger, H., and Pfeiffer, K. (2000) Supercomplexes in the respiratory chains of yeast and mammalian mitochondria, EMBO J. 19, 1773-1783.

31. Shimada, S., Shinzawa-Itoh, K., Baba, J., Aoe, S., Shimada, A., Yamashita, E., Kang, J., Tateno, M., Yoshikawa, S., and Tsukihara, T. (2017) Complex structure of cytochrome ccytochrome c oxidase reveals a novel protein-protein interaction mode, EMBO J., 36, 291-300.

32. Ferguson-Miller, S., Brautigan, D.L., and Margoliash, E. (1978) Definition of cytochrome $c$ binding domains by chemical modification. III. Kinetics of reaction of carboxydinitrophenyl cytochromes $c$ with cytochrome $c$ oxidase, J. Biol. Chem. 253, 149-159.

33. Osheroff, N., Brautigan, D.L., and Margoliash, E. (1980) Definition of Enzymic Interaction Domains on Cytochrome c. J. Biol. Chem. $255,8245-8251$.

34. Moser, C.C., Keske, J.M., Warncke, K., Farid, R.S., and Dutton, P.L. (1992) Nature of biological electron transfer, Nature 355, 796802. 
35. Pilet, E., Jasaitis, A., Liebl, U., and Vos, M.H. (2004) Electron transfer between hemes in mammalian cytochrome $c$ oxidase, Proc. Natl. Acad. Sci. USA 101, 16198-16203.

36. Mitchell, R., Mitchell, P., and Rich, P.R. (1992) Protonation states of the catalytic cycle intermediates of cytochrome $c$ oxidase, Biochim. Biophys. Acta Bioenergetics 1101, 188-191.

37. Mitchell, R., and Rich, P.R. (1994) Proton uptake by cytochrome $c$ oxidase on reduction and on ligand binding, Biochim. Biophys.

Acta. 1186, 19-26.

38. Wikström, M. (2012) Active site intermediates in the reduction of $\mathrm{O}_{2}$ by cytochrome oxidase, and their derivatives, Biochim. Biophys. Acta 1817, 468-475.

39. Moody, A.J. (1996) 'As prepared' forms of fully oxidised haem/Cu terminal oxidases, Biochim. Biophys. Acta 1276, 6-20.

40. Aoyama, H., Muramoto, K., Shinzawa-Itoh, K., Hirata, K., Yamashita, E., Tsukihara, T., Ogura, T., and Yoshikawa, S. (2009) A peroxide bridge between $\mathrm{Fe}$ and $\mathrm{Cu}$ ions in the $\mathrm{O}_{2}$ reduction site of fully oxidized cytochrome c oxidase could suppress the proton pump, Proc. Natl. Acad. Sci. USA 106, 2165-2169.

41. Koepke, J., Olkhova, E., Angerer, H., Muller, H., Peng, G.H., and Michel, H. (2009) High resolution crystal structure of Paracoccus denitrificans cytochrome $c$ oxidase: New insights into the active site and the proton transfer pathways, Biochimica et Biophysica Acta Bioenergetics 1787, 635-645.

42. Mochizuki, M., Aoyama, H., Shinzawa-Itoh, K., Tsukihara, T., and Yoshikawa, S. (1999) Quantitative reevaluation of the redox sites of crystalline bovine heart cytochrome $c$ oxidase, J. Biol. Chem. 274, 33403-33411.

43. Qin, L., Liu, J., Mills, D.A., Proshlyakov, D.A., Hiser, C., and Ferguson-Miller, S. (2009) Redox-dependent conformational changes in cytochrome $c$ oxidase suggest a gating mechanism for proton uptake, Biochemistry 48, 5121-5130.

44. Liu, J., Qin, L., and Ferguson-Miller, S. (2011) Crystallographic and online spectral evidence for role of conformational change and conserved water in cytochrome oxidase proton pump, Proc. Natl. Acad. Sci. USA 108, 1284-1289. 
45. Rich, P.R. (1995) Towards an understanding of the chemistry of oxygen reduction and proton translocation in the iron-copper respiratory oxidases, Aust. Journ. Plant. Physiol. 22, 479-486.

46. Iwaki, M., Puustinen, A., Wikström, M., and Rich, P.R. (2006) Structural and chemical changes of the $\mathrm{P}_{\mathrm{M}}$ intermediate of Paracoccus denitrificans cytochrome $c$ oxidase revealed by IR spectroscopy with labeled tyrosines and histidines, Biochemistry $45,10873-10885$.

47. Gorbikova, E.A., Belevich, N.P., Wikström, M., and Verkhovsky, M.I. (2007) Protolytic reactions on reduction of cytochrome $c$ oxidase studied by ATR-FTIR spectroscopy, Biochemistry 46, 4177-4183.

48. Verkhovsky, M.I., Jasaitis, A., Verkhovskaya, M.L., Morgan, J.E., and Wikström, M. (1999) Proton translocation by cytochrome C oxidase, Nature 400, 480-483.

49. Sharma, V., Karlin, K.D., and Wikström, M. (2013) Computational study of the activated $\mathrm{OH}$ state in the catalytic mechanism of cytochrome c oxidase, Proc. Natl. Acad. Sci. USA 110, 1684416849.

50. Ogura, T., Takahashi, S., Hirota, S., Shinzawa-Itoh, K., Yoshikawa, S., Appelman, E.H., and Kitagawa, T. (1993) Timeresolved resonance Raman elucidation of the pathway for dioxygen reduction by cytochrome $c$ oxidase, J. Am. Chem. Soc. $115,8527-8536$.

51. Han, S., Takahashi, S., and Rousseau, D.L. (2000) Time dependence of the catalytic intermediates in cytochrome $C$ oxidase, J. Biol. Chem. 275, 1910-1919.

52. Blomberg, M.R.A. (2015) Mechanism of Oxygen Reduction in Cytochrome c Oxidase and the Role of the Active Site Tyrosine, Biochemistry 55, 489-500.

53. Blomberg, M.R.A., and Siegbahn, P.E.M. (2015) Protonation of the binuclear active site in cytochrome c oxidase decreases the reduction potential of $\mathrm{Cu}_{\mathrm{B}}$, Biochim. Biophys. Acta 1847, 11731180. 
54. Blomberg, M.R.A., and Siegbahn, P.E.M. (2015) How cytochrome $C$ oxidase can pump four protons per oxygen molecule at high electrochemical gradient, Biochim. Biophys. Acta 1847, 364-376.

55. Chance, B., Saronio, C., and Leigh, J.S. (1975) Functional intermediates in the reaction of membrane-bound cytochrome oxidase with oxygen, J. Biol. Chem. 250, 9226-9237.

56. Babcock, G.T. (1999) How oxygen is activated and reduced in respiration, Proc. Natl. Acad. Sci. USA 96, 12971-12973.

57. Proshlyakov, D.A., Pressler, M.A., DeMaso, C., Leykam, J.F., DeWitt, D.L., and Babcock, G.T. (2000) Oxygen activation and reduction in respiration: Involvement of redox-active tyrosine 244, Science 290, 1588-1591.

58. Sharma, V., and Wikström, M.K.F. (2016) The role of the Kchannel and the active-site tyrosine in the catalytic mechanism of cytochrome c oxidase, Biochim. Biophys. Acta Bioenergetics 1857, 1111-1115.

59. Murphy, M.P. (2009) How mitochondria produce reactive oxygen species, Biochem. J. 417, 1-13.

60. Gorbikova, E.A., Wikström, M., and Verkhovsky, M.I. (2008) The protonation state of the cross-linked tyrosine during the catalytic cycle of cytochrome c oxidase, J. Biol. Chem. 283, 34907-34912.

61. Proshlyakov, D.A., Ogura, T., Shinzawa-Itoh, K., Yoshikawa, S., and Kitagawa, T. (1996) Resonance Raman/absorption characterization of the oxo intermediates of cytochrome $c$ oxidase generated in its reaction with hydrogen peroxide: $\mathrm{pH}$ and $\mathrm{H}_{2} \mathrm{O}_{2}$ concentration dependence, Biochemistry 35, 8580-8586.

62. Proshlyakov, D.A., Ogura, T., Shinzawa-Itoh, K., Yoshikawa, S., Appelman, E.H., and Kitagawa, T. (1994) Selective resonance Raman observation of the "607 nm" form generated in the reaction of oxidized cytochrome $c$ oxidase with hydrogen peroxide, J. Biol. Chem. 269, 29385-29388.

63. Gibson, Q.H., and Greenwood, C. (1963) Reactions of cytochrome oxidase with oxygen and carbon monoxide, Biochem. J. 86, 541554. 
64. Morgan, J.E., Verkhovsky, M.I., and Wikstrom, M. (1996)

Observation and assignment of peroxy and ferryl intermediates in the reduction of dioxygen to water by cytochrome $c$ oxidase, Biochemistry 35, 12235-12240.

65. Morgan, J.E., Verkhovsky, M.I., Palmer, G., and Wikström, M. (2001) The role of the $P_{R}$ intermediate of cytochrome $c$ oxidase with $\mathrm{O}_{2}$, Biochemistry 40, 6882-6892.

66. Yano, N., Muramoto, K., Shimada, A., Takemura, S., Baba, J., Fujisawa, H., Mochizuki, M., Shinzawa-Itoh, K., Yamashita, E., Tsukihara, T., and Yoshikawa, S. (2016) The Mg2+-containing water cluster of mammalian cytochrome c oxidase collects four pumping proton equivalents in each catalytic cycle, J. Biol. Chem. 291, 2382-2394.

67. Nagle, J.F., and Tristram-Nagle, S. (1983) Hydrogen bonded chain mechanisms for proton conduction and proton pumping, $\mathrm{J}$. Membrane Biol. 74, 1-14.

68. DeCoursey, T.E. (2003) Voltage-gated proton channels and other proton transfer pathways, Physiological Reviews 83, 475-579.

69. Grotthuss, C.J.T. (2006) (Translated version of) Memoir on the decomposition of water and of the bodies that it holds in solution by means of galvanic electricity, Biochim. Biophys. Acta Bioenergetics 1757, 871-875.

70. Yoshikawa, S., Shinzawa-Itoh, K., Nakashima, R., Yaono, R., Yamashita, E., Inoue, N., Yao, M., Fei, M.J., Libeu, C.P., Mizushima, T., Yamaguchi, H., Tomizaki, T., and Tsukihara, T. (1998) Redox-coupled crystal structural changes in bovine heart cytochrome c oxidase, Science 280, 1723-1729.

71. Bloch, D., Belevich, I., Jasaitis, A., Ribacka, C., Puustinen, A., Verkhovsky, M.I., and Wikström, M. (2004) The catalytic cycle of cytochrome $c$ oxidase is not the sum of its two halves, Proc. Natl. Acad. Sci. USA 101, 529-533.

72. Faxén, K., Gilderson, G., Ädelroth, P., and Brzezinski, P. (2005) A mechanistic principle for proton pumping by cytochrome $c$ oxidase, Nature 437, 286-289. 
73. Wikström, M., Sharma, V., Kaila, V.R.I., Hosler, J.P., and Hummer, G. (2015) New Perspectives on Proton Pumping in Cellular Respiration, Chem. Rev. 115, 2196-2221.

74. Lee, H.-M., Das, T.K., Rousseau, D.L., Mills, D., Ferguson-Miller, S., and Gennis, R.B. (2000) Mutations in the putative H-channel in the cytochrome $c$ oxidase from Rhodobacter sphaeroides show that this channel is not important for proton conduction but reveal modulation of the properties of heme a, Biochemistry 39, 29892996.

75. Ädelroth, P., Gennis, R.B., and Brzezinski, P. (1998) Role of the pathway through $\mathrm{K}(\mathrm{I}-362)$ in proton transfer in cytochrome $C$ oxidase from R. sphaeroides, Biochemistry 36, 2470-2476.

76. Konstantinov, A.A., Siletsky, S., Mitchell, D., Kaulen, A., and Gennis, R.B. (1997) The roles of the two proton input channels in cytochrome $c$ oxidase from Rhodobacter sphaeroides probed by the effects of site-directed mutations on time-resolved electrogenic intraprotein proton transfer, Proc. Natl. Acad. Sci. USA 94, 90859090.

77. Han, D., Namslauer, A., Pawate, A., Morgan, J.E., Nagy, A.S., Vakkasoglu, P., Brzezinski, P., and Gennis, R.B. (2006) Replacing Asn207 by aspartate at the neck of the $D$ channel in the $a a_{3}$-type cytochrome $c$ oxidase from Rhodobacter sphaeroides results in decoupling the proton pump, Biochemistry 45, 14064-14074.

78. Pfitzner, U., Hoffmeier, K., Harenga, A., Kannt, A., Michel, H., Bamberg, E., Richter, O.-M.H., and Ludwig, B. (2000) Tracing the $D$-pathway in reconstituted site-directed mutants of cytochome $\mathrm{C}$ oxidase fom Paracoccus denitrificans, Biochemistry 39, 67566762.

79. Zaslavsky, D., and Gennis, R. (2000) Proton pumping by cytochrome oxidase: progress, problems and postulates, Biochim. Biophys. Acta 1458, 164-179.

80. Hellwig, P., Behr, J., Ostermeier, C., Richter, O.-M.H., Pfitzner, U., Odenwald, A., Ludwig, B., Michel, H., and Mäntele, W. (1998) Involvement of glutamic acid 278 in the redox reaction of the cytochrome $c$ oxidase from Paracoccus denitrificans investigated by FTIR spectroscopy, Biochemistry 37, 7390-7399. 
81. Supekar, S., Gamiz-Hernandez, A.P., and Kaila, V.R.I. (2016) A Protonated Water Cluster as a Transient Proton-Loading Site in Cytochrome c Oxidase, Angew. Chem. 128, 12119-12123.

82. Rich, P.R., and Maréchal, A. (2013) Functions of the hydrophilic channels in protonmotive cytochrome $c$ oxidase, J. Roy. Soc. Interface 10, 1-14.

83. Jünemann, S., Meunier, B., Gennis, R.B., and Rich, P.R. (1997) Effects of mutation of the conserved lysine-362 in cytochrome $C$ oxidase from Rhodobacter sphaeroides, Biochemistry 36, 1445614464.

84. Lepp, H., Svahn, E., Faxén, K., and Brzezinski, P. (2008) Charge transfer in the $\mathrm{K}$ proton pathway linked to electron transfer to the catalytic site in cytochrome $c$ oxidase, Biochemistry 47, 49294935.

85. Wikström, M., Verkhovsky, M.I., and Hummer, G. (2003) Watergated mechanism of proton translocation by cytochrome $c$ oxidase, Biochim. Biophys. Acta 1604, 61-65.

86. Kim, Y.C., Wikström, M., and Hummer, G. (2009) Kinetic gating of the proton pump in cytochrome $c$ oxidase, Proc. Natl. Acad. Sci. USA 106, 13707-13712.

87. Siegbahn, P.E.M., Blomberg, M.R.A., and Blomberg, M.L. (2003) Theoretical Study of the Energetics of Proton Pumping and Oxygen Reduction in Cytochrome Oxidase, J. Phys. Chem. B 107, 10946-10955.

88. Blomberg, M.R.A., and Siegbahn, P.E.M. (2012) The mechanism for proton pumping in cytochrome $c$ oxidase from an electrostatic and quantum chemical perspective, Biochim. Biophys. Acta Bioenergetics 1817, 495-505.

89. Wikström, M., Ribacka, C., Molin, M., Laakkonen, L., Verkhovsky, M., and Puustinen, A. (2005) Gating of proton and water transfer in the respiratory enzyme cytochrome c oxidase, Proc. Natl. Acad. Sci. USA 102, 10478-10481.

90. Maréchal, A., and Rich, P.R. (2011) Water molecule reorganization in cytochrome $c$ oxidase revealed by FTIR spectroscopy, Proc. Natl. Acad. Sci. USA 108, 8634-8638. 
91. Han, H., Hemp, J., Pace, L.A., Ouyang, H., Ganesan, K., Roh, J.H., Daldal, F., Blanke, S.R., and Gennis, R.B. (2011) Adaptation of aerobic respiration to low $\mathrm{O}_{2}$ environment, Proc. Natl. Acad. Sci. USA 108, 14109-14114.

92. Shimokata, K., Katayama, Y., Murayama, H., Suematsu, M., Tsukihara, T., Muramoto, K., Aoyama, H., Yoshikawa, S., and Shimada, H. (2007) The proton pumping pathway of bovine heart cytochrome c oxidase, Proc. Natl. Acad. Sci. USA 104, 4200-4205.

93. Kubo, M., Nakashima, S., Yamaguchi, S., Ogura, T., Mochizuki, M., Kang, J., Tateno, M., Shinzawa-Itoh, K., Kato, K., and Yoshikawa, S. (2013) Effective pumping proton collection facilitated by a copper site $\left(\mathrm{Cu}_{\mathrm{B}}\right)$ of bovine heart cytochrome $c$ oxidase, revealed by a newly developed time-resolved infrared system, J. Biol. Chem. 288, 30259-30269.

94. Tsukihara, T., Shimokata, K., Katayama, Y., Shimada, H., Muramoto, K., Aoyama, H., Mochizuki, M., Shinozawa-Itoh, K., Yamashita, E., Yao, M., Ishimura, Y., and Yoshikawa, S. (2003) The low-spin heme of cytochrome $c$ oxidase as the driving element of the proton-pumping process, Proc. Natl. Acad. Sci. USA 100, 15304-15309.

95. Maréchal, A., Haraux, F., Meunier, B., and Rich, P.R. (2014) Determination of $\mathrm{H}^{+}$le ratios in mitochondrial yeast cytochrome $c$ oxidase, Biochim. Biophys. Acta Bioenergetics 1837, e100.

96. Maréchal, A., Xu, J.P., Genko, N., Meunier, B., and Rich, P.R. (2017) Identification of the proton pumping channel in yeast mitochondrial cytochrome $c$ oxidase, manuscript in preparation.

97. Belevich, I., Bloch, D.A., Belevich, N., Wikström, M., and Verkhovsky, M.I. (2007) Exploring the proton pump mechanism of cytochrome c oxidase in real time, Proc. Natl. Acad. Sci. USA 104, 2685-2690.

98. Belevich, I., Gorbikova, E., Belevich, N.P., Rauhamäki, V., Wikström, M., and Verkhovsky, M.I. (2010) Initiation of the proton pump of cytochrome $c$ oxidase, Proc. Natl. Acad. Sci. USA 107, 18469-18474.

\section{Figure legends}


Figure 1. Overall structure and cofactors of mammalian cytochrome c oxidase. The approximate position of a 13-subunit monomer of mammalian $\mathrm{CcO}$ (redrawn from PDB entry $1 \mathrm{~V} 54$ ) within the inner mitochondrial membrane is shown. The three core subunits that are encoded by the mitochondrial genome are shown in green (subunit I), purple (subunit II) and blue (subunit III). The 10 nuclear-encoded subunits are shown in grey. Cytochrome $c$ in the IMS sequentially donates four electrons. These are accepted initially by the dinuclear $\mathrm{Cu}_{\mathrm{A}}$ centre in subunit II before being transferred via the low spin haem a into the haem $\mathrm{a}_{3} / \mathrm{Cu}_{\mathrm{B}}$ binuclear centre (BNC). Molecular oxygen enters the $\mathrm{BNC}$ from the membrane phase through subunit III. There it is reduced to two water molecules with the uptake of four protons $\left(4 \mathrm{H}_{\mathrm{N}}{ }^{+}\right)$from the $\mathrm{N}$ phase matrix. During one complete catalytic cycle, four additional protons are translocated from the $\mathrm{N}$ phase matrix $\left(4 \mathrm{H}_{\mathrm{N}}{ }^{+}\right)$to the $\mathrm{P}$ phase IMS $\left(4 \mathrm{H}_{\mathrm{P}}^{+}\right)$.

Figure 2. Structure of the catalytic binuclear centre. The left-hand figure is a top view of the low spin bis-histidine-ligated haem a and the $\mathrm{BNC}$ formed from histidine-coordinated haem $\mathrm{a}_{3}$ and $\mathrm{Cu}_{\mathrm{B}}$. The closest distance between the haem macrocycles is $\sim 7 \AA$. The right-hand figure is a side view of the BNC, showing the catalytic tyrosine (Y244) that is covalently linked to $\mathrm{Cu}_{B}$ ligand $\mathrm{H} 240$. The separation of the BNC metals is $\sim 5 \AA$ and possible ligands between them are discussed in the text.

Figure 3. Hydrophilic pathways within subunit I. The D channel connects $\mathrm{N}$ phase $\mathrm{D} 91$ to $\mathrm{E} 242$; the $\mathrm{K}$ channel connects the $\mathrm{N}$ phase to $\mathrm{Y} 244$ in the BNC; the $\mathrm{H}$ channel connects the $\mathrm{N}$ phase via the formyl and propionate on the A pyrrole of haem a to the P phase at D51. Water molecules identified in the crystal structure are shown as blue spheres

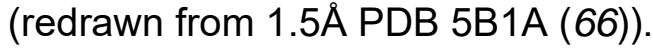

\section{Figure 4. The catalytic cycle of oxygen reduction.}

The main BNC catalytic intermediates of the protonmotive reaction cycle are shown in black. Starting with the active oxidised form, $\mathrm{O}_{\mathrm{H}}$, two sequential electron transfers reduce it to the active Electronated state $\left(E_{H}\right)$ and then to the Reduced $(R)$ form. Oxygen binds to R to produce the oxyferrous intermediate $A$. This spontaneously decomposes into $P$. $P$ is reduced with two electron transfers, firstly to $F$ and then back to $\mathrm{O}_{\mathrm{H}}$. All four electron input steps cause net binding of a charge-compensating proton from the $\mathrm{N}$ phase $\left(\mathrm{H}_{\mathrm{N}}{ }^{+}\right)$and are also linked to a translocation of a proton from the $\mathrm{N}$ to the $\mathrm{P}$ phase (red arrows). Conversion of $\mathrm{A}$ into $\mathrm{F}$ can proceed via a pathway in which an extra electron is transferred from haem $a$ into the $A$ intermediate to form a species shown as $P_{R}$. $P_{R}$ hence 
has one more electron than $\mathrm{P}$; protonation of $\mathrm{P}_{\mathrm{R}}$ converts it to $\mathrm{F}$. The non-protonmotive oxidised form $(\mathrm{O})$ is shown in gray. This is reduced to $\mathrm{R}$ with two charge-compensated electron/proton transfers but is not linked to proton translocation. Details are given in the text.

\section{Figure 5. Likely chemical structures of the BNC catalytic} intermediates.

The possible chemical identities of the catalytic intermediates of figure 4 are shown in terms of the redox and protonation states of the metals, the catalytic tyrosine and associated water/hydroxides. Specific details are given in the text.

\section{Figure 6. A general mechanism of coupling of electron transfer to} proton translocation in A-type CcOs. A:- Haem a is oxidised, E242 at the top of the $D$ channel is protonated, a proton trap region 'above' the BNC has a pK too low to accept a proton. B:- The pK of the trap site is raised when haem $a$ is reduced and further raised the electron transfers into the BNC. The trap becomes protonated with a proton from E242, stabilised by the negative charge of the reduced BNC. E242 reprotonates via the $\mathrm{D}$ channel. $\mathbf{C}$ :- Reduction creates a high $\mathrm{pK}$ group within the BNC (see Figure 4). This drives protonation of the BNC from the $\mathrm{N}$ phase, via the E242/D or the K pathway, depending on step of the oxygen reduction cycle. D:- The BNC change is now electroneutral. Hence, the $\mathrm{pK}$ of the trap site decreases and gating ensures that the proton is expelled into the $P$ phase. The cycle continues with the next step of the oxygen reduction cycle, with a similar coupling sequence occurring at each step of BNC reduction.

Figure 7. A proposed mechanism of coupling of electron transfer to proton translocation in mammalian forms of $\mathrm{CcO}$. In this scheme (24), the release of a proton into the $P$ phase again occurs in each of the four $\mathrm{BNC}$ reduction steps. However, substrate protons are proposed to be bound only in the $\mathrm{P} \rightarrow \mathrm{F} \rightarrow \mathrm{O}_{\mathrm{H}}$ steps and the uptake of all four translocated protons into the trap region is proposed to occur in a single step after BNC reduction (shown as $R_{1} \rightarrow R_{2}$ ) via the $H$ channel. 
Figure 1

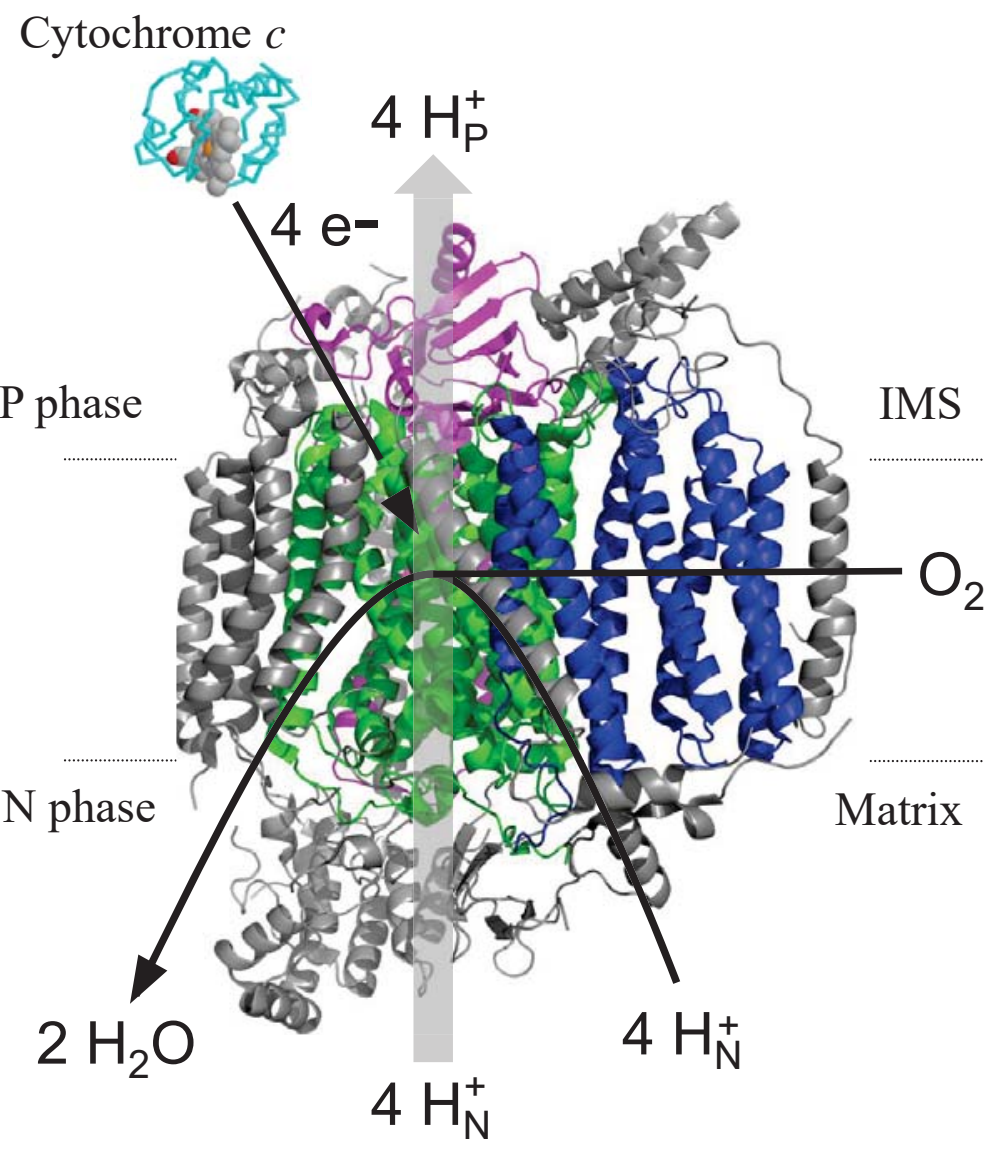

Cytochrome $c$

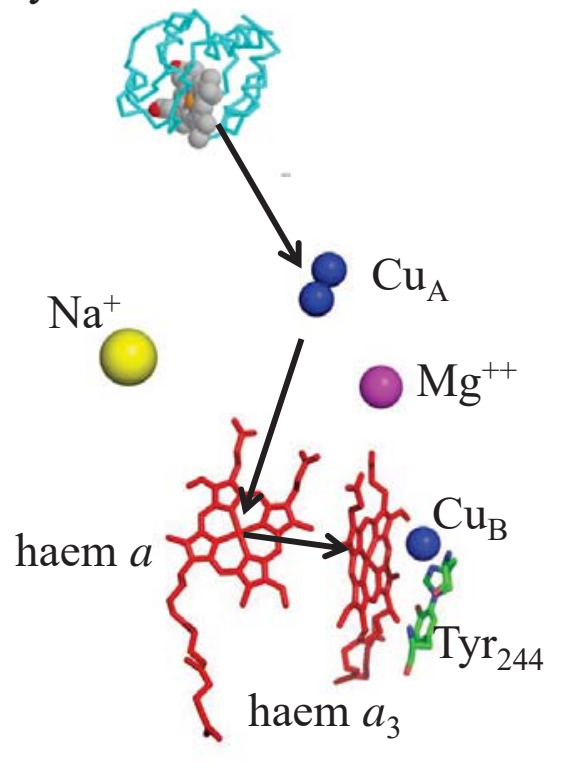


Figure 2

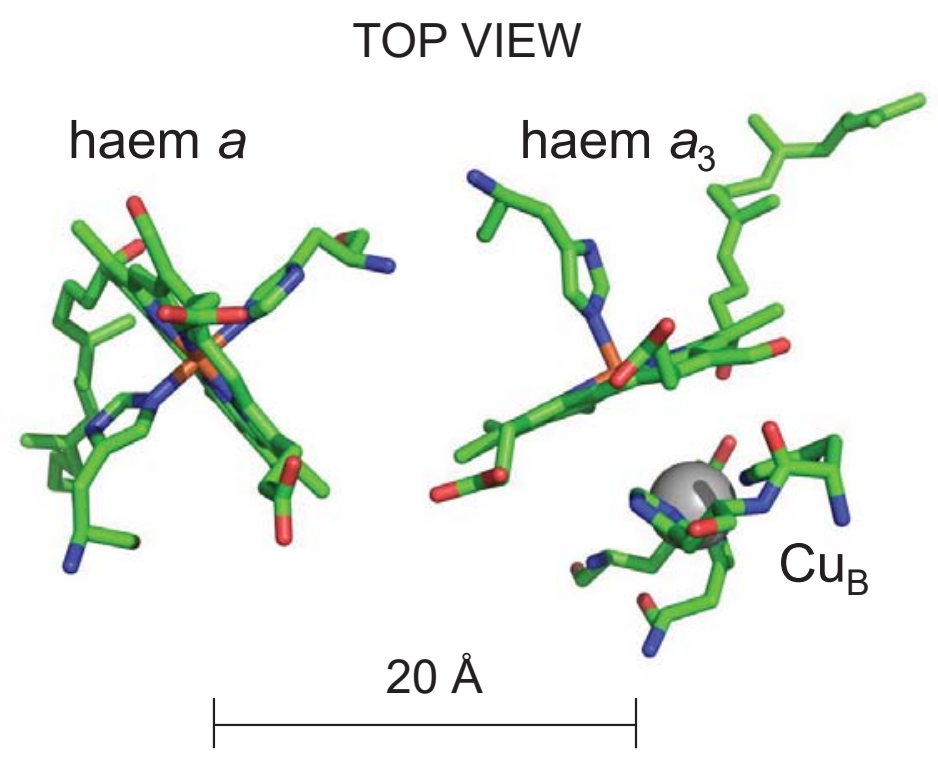

BNC - SIDE VIEW

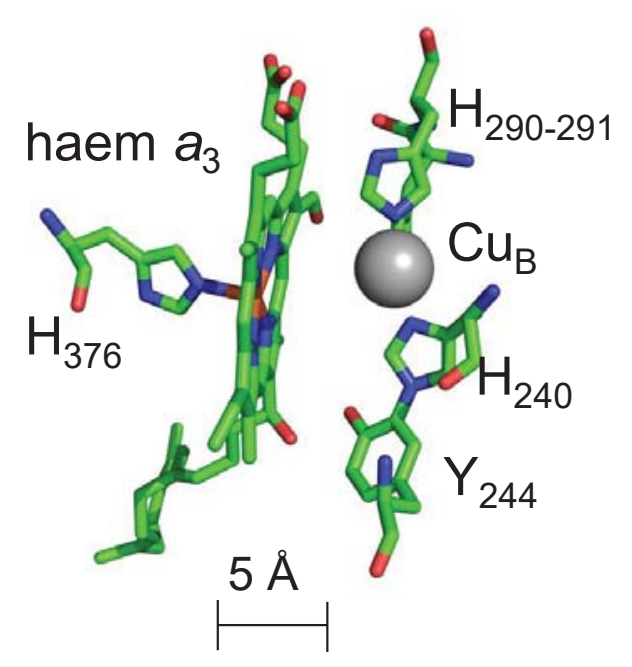


Figure 3

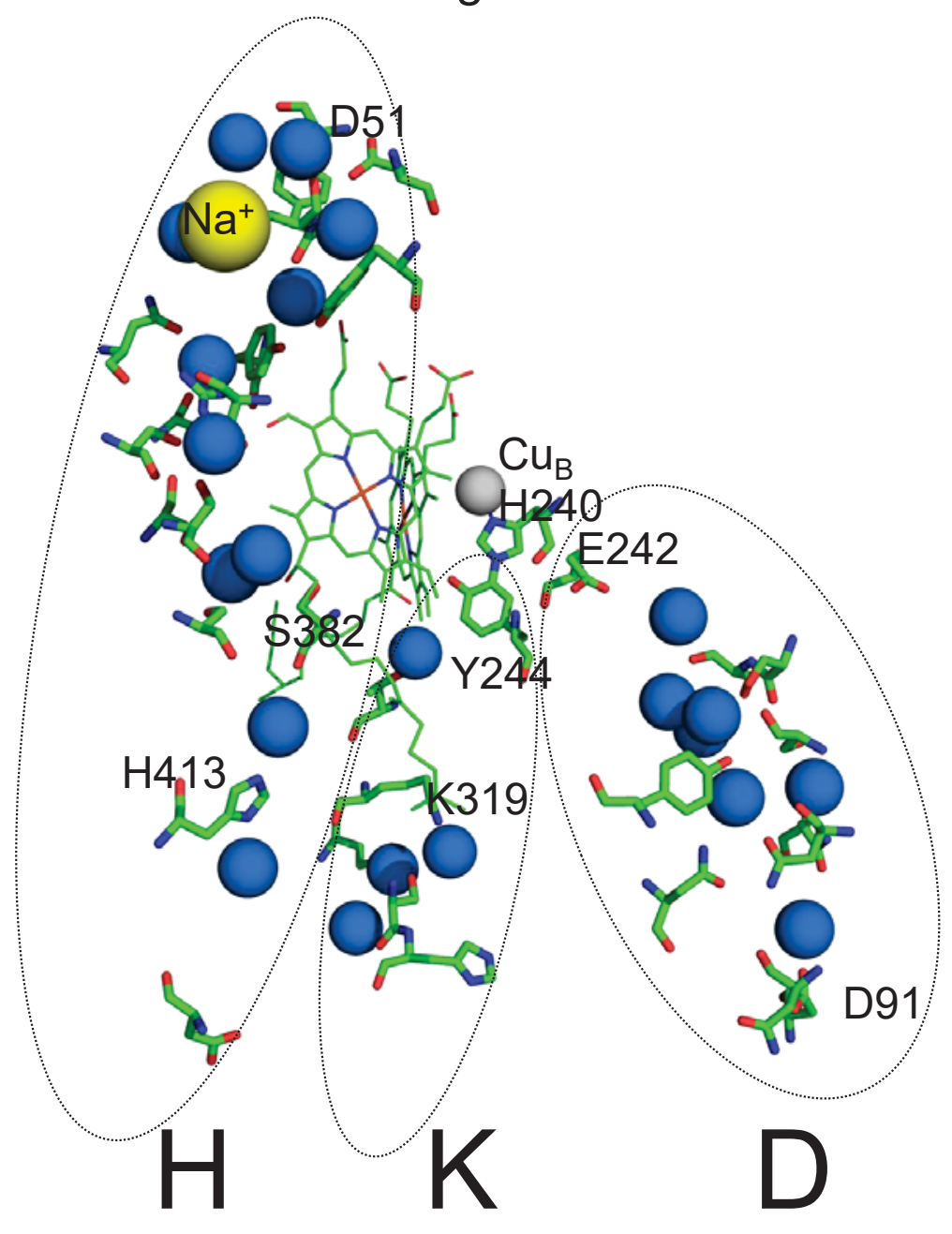


Figure 4

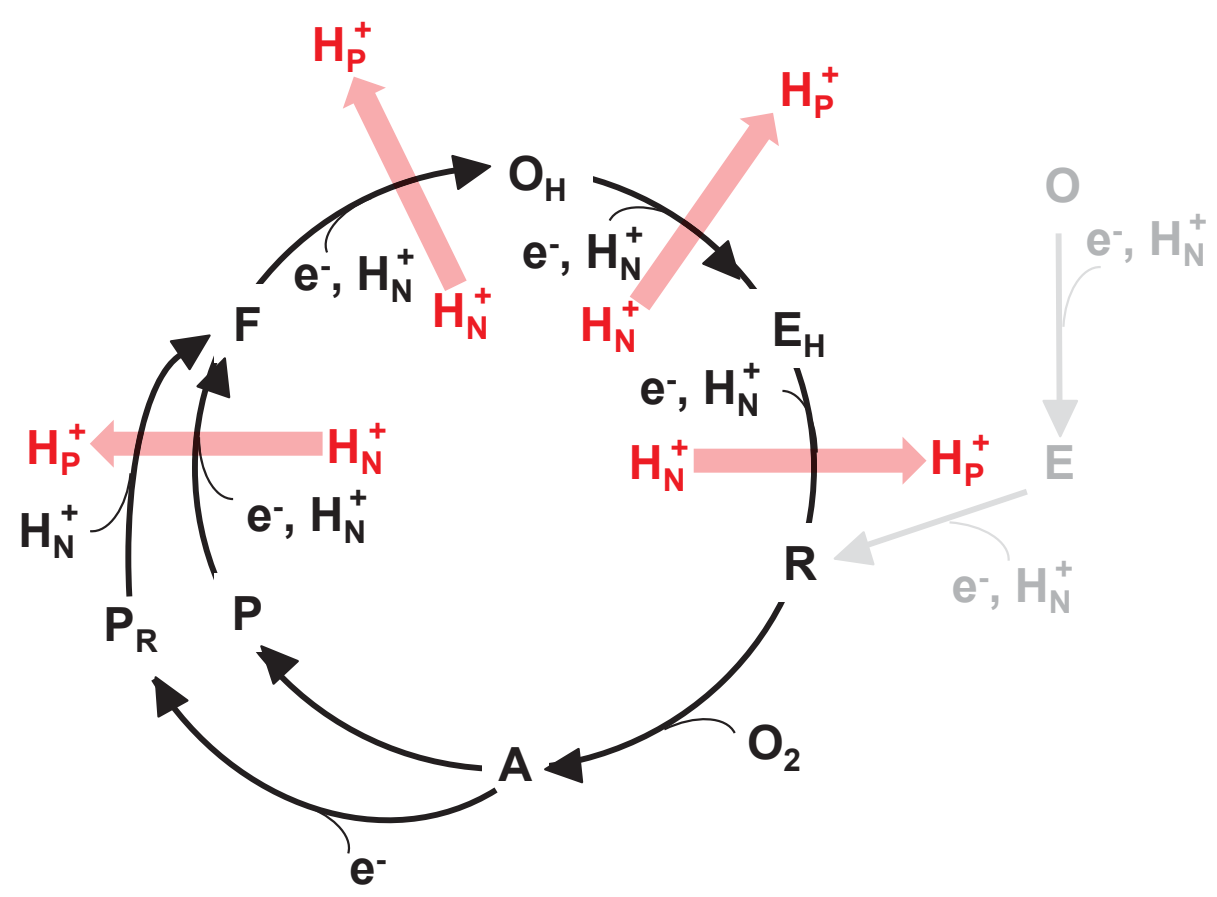


Figure 6

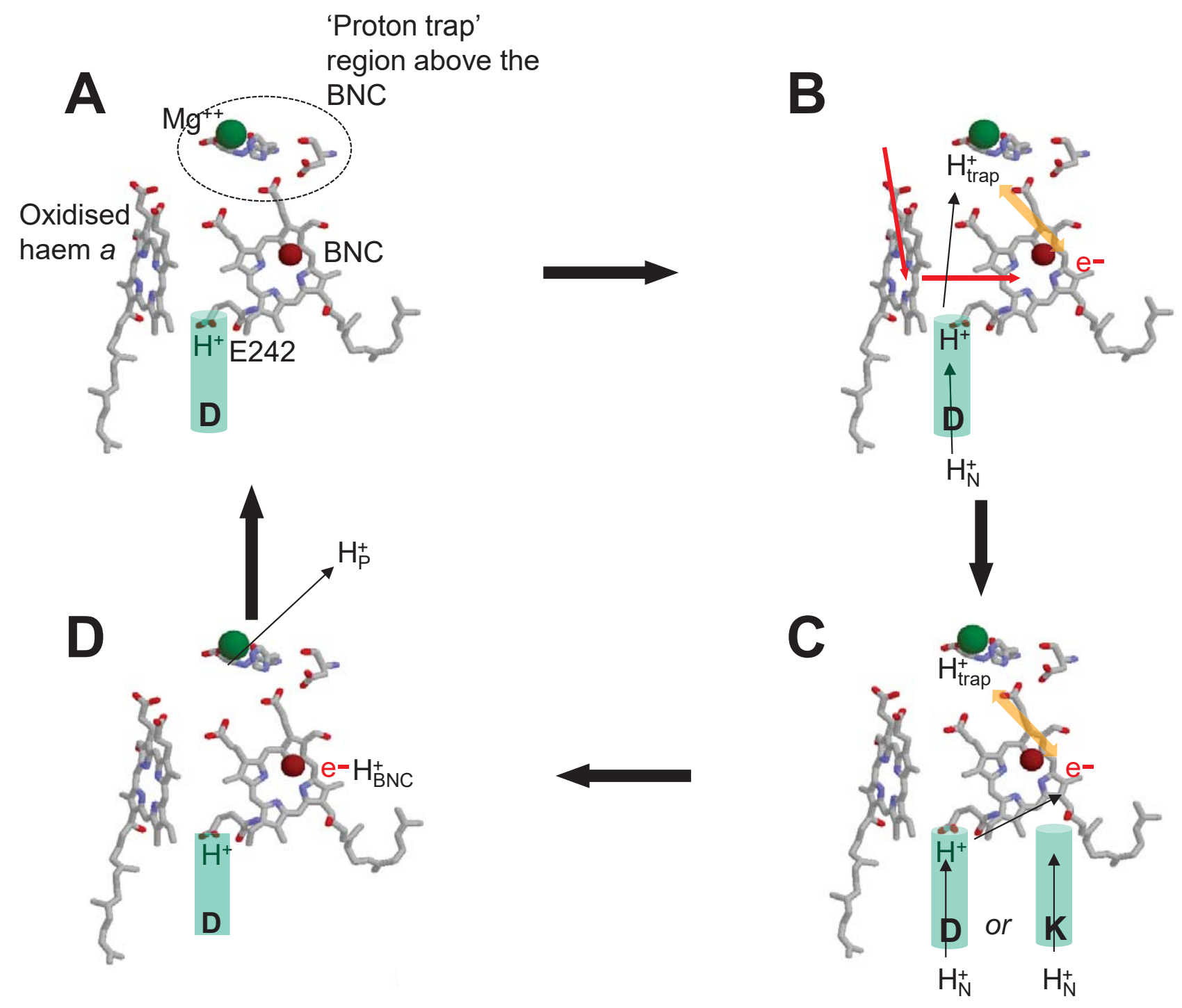


Figure 7

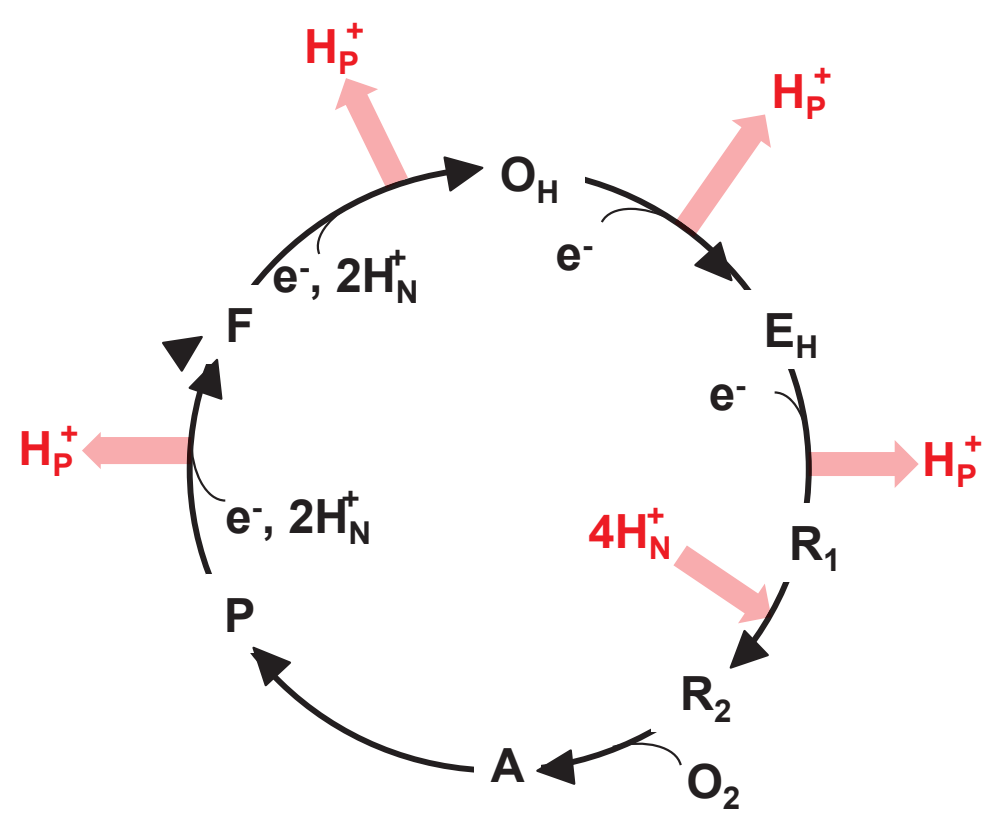

